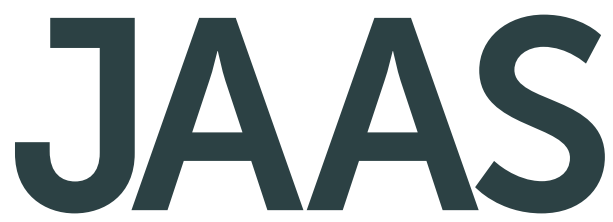

Journal of Analytical Atomic Spectrometry www.rsc.org/jaas
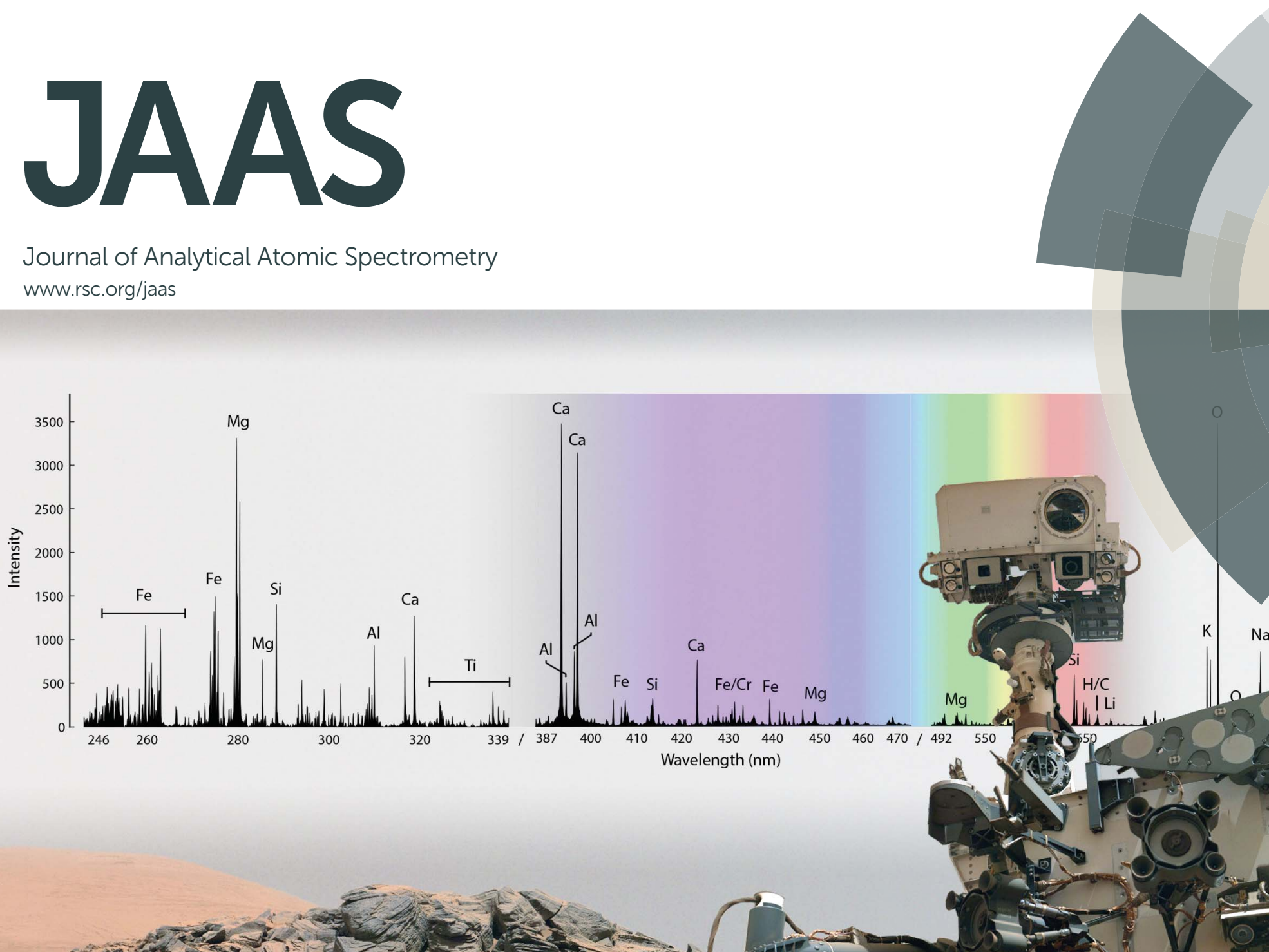


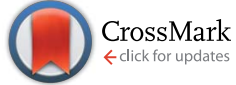

Cite this: J. Anal. At. Spectrom., 2016, 31,863

Received 19th October 2015 Accepted 16th February 2016

DOI: 10.1039/c5ja00417a

www.rsc.org/jaas

\section{ChemCam activities and discoveries during the nominal mission of the Mars Science Laboratory in Gale crater, Mars}

S. Maurice, ${ }^{\text {a }}$ S. M. Clegg, ${ }^{\text {b }}$ R. C. Wiens, ${ }^{\text {b }}$ O. Gasnault, ${ }^{a}$ W. Rapin, ${ }^{a}$ O. Forni, ${ }^{a}$ A. Cousin, ${ }^{a}$ V. Sautter, ${ }^{c}$ N. Mangold, ${ }^{d}$ L. Le Deit, ${ }^{d}$ M. Nachon, ${ }^{d}$ R. B. Anderson, ${ }^{e}$ N. L. Lanza, ${ }^{b}$ C. Fabre, ${ }^{f}$ V. Payré, ${ }^{f}$ J. Lasue, ${ }^{a}$ P.-Y. Meslin, ${ }^{a}$ R. J. Léveillé, ${ }^{\text {gh }}$ B. L. Barraclough, ${ }^{b}$ P. Beck, ${ }^{i}$ S. C. Bender, ${ }^{j}$ G. Berger, ${ }^{a}$ J. C. Bridges, ${ }^{k}$ N. T. Bridges, ${ }^{,}$G. Dromart, ${ }^{m}$ M. D. Dyar, ${ }^{n}$ R. Francis, ${ }^{\text {op }}$ J. Frydenvang, ${ }^{\mathrm{b}}$ B. Gondet, ${ }^{\mathrm{a}}$ B. L. Ehlmann, ${ }^{\mathrm{p}}$ K. E. Herkenhoff, ${ }^{\mathrm{e}}$ J. R. Johnson, 'Y. Langevin, ${ }^{a}$ M. B. Madsen, ${ }^{r}$ N. Melikechi, ${ }^{\mathrm{s}} \mathrm{J}$.-L. Lacour, ${ }^{\mathrm{t}} \mathrm{S}$. Le Mouélic, ${ }^{d}$ E. Lewin, ${ }^{\mathrm{u}}$ H. E. Newsom, ${ }^{\vee}$ A. M. Ollila, ${ }^{\vee}$ P. Pinet, ${ }^{a}$ S. Schröder, ${ }^{a}$ J.-B. Sirven, ${ }^{\mathrm{t}}$ R. L. Tokar, ${ }^{\mathrm{j}}$ M. J. Toplis, ${ }^{a}$ C. d'Uston, ${ }^{a}$ D. T. Vaniman ${ }^{j}$ and A. R. Vasavada ${ }^{p}$

At Gale crater, Mars, ChemCam acquired its first laser-induced breakdown spectroscopy (LIBS) target on Sol 13 of the landed portion of the mission (a Sol is a Mars day). Up to Sol 800, more than 188000 LIBS spectra were acquired on more than 5800 points distributed over about 650 individual targets. We present a comprehensive review of ChemCam scientific accomplishments during that period, together with a focus on the lessons learned from the first use of LIBS in space. For data processing, we describe new tools that had to be developed to account for the uniqueness of Mars data. With regard to chemistry, we present a summary of the composition range measured on Mars for major-element oxides $\left(\mathrm{SiO}_{2}, \mathrm{TiO}_{2}\right.$, $\mathrm{Al}_{2} \mathrm{O}_{3}, \mathrm{FeO}_{\mathrm{T}}, \mathrm{MgO}, \mathrm{CaO}, \mathrm{Na}_{2} \mathrm{O}, \mathrm{K}_{2} \mathrm{O}$ ) based on various multivariate models, with associated precisions. ChemCam also observed $\mathrm{H}$, and the non-metallic elements $\mathrm{C}, \mathrm{O}, \mathrm{P}$, and $\mathrm{S}$, which are usually difficult to quantify with LIBS. $\mathrm{F}$ and $\mathrm{Cl}$ are observed through their molecular lines. We discuss the most relevant LIBS lines for detection of minor and trace elements ( $\mathrm{Li}, \mathrm{Rb}, \mathrm{Sr}, \mathrm{Ba}, \mathrm{Cr}, \mathrm{Mn}, \mathrm{Ni}$, and $\mathrm{Zn}$ ). These results were obtained thanks to comprehensive ground reference datasets, which are set to mimic the expected mineralogy and chemistry on Mars. With regard to the first use of LIBS in space, we analyze and quantify, often for the first time, each of the advantages of using stand-off LIBS in space: no sample preparation, analysis within its petrological context, dust removal, sub-millimeter scale investigation, multi-point analysis, the ability to carry out statistical surveys and whole-rock analyses, and rapid data acquisition. We conclude with a discussion of ChemCam performance to survey the geochemistry of Mars, and its valuable support of decisions about selecting where and whether to make observations with more time and resource-intensive tools in the rover's instrument suite. In the end, we present a bird's-eye view of
aIRAP, Univ. Paul Sabatier - CNRS - Obs. Midi-Pyrénées, 9 av. colonel Roche, 31400 Toulouse, France. E-mail: maurice@cesr.fr; Fax: +33 56155 67 01; Tel: +33 61878 5292

${ }^{b}$ Los Alamos National Laboratory, Los Alamos, NM, USA

'IMPMC, Museum National d'Histoire Naturelle, Paris, France

${ }^{d}$ Laboratoire de Planétologie et Géodynamique, LPG-Nantes, UMR CNRS, 6112, France

${ }^{e}$ U.S. Geological Survey, Astrogeology Science Center, Flagstaff, AZ, USA

${ }^{f}$ GeoRessources - Université de Lorraine, Vandoeuvre les Nancy, France

${ }^{g}$ Canadian Space Agency, Saint-Hubert, Quebec, Canada

${ }^{h}$ Department of Natural Resource Sciences, McGill University, Montreal, Quebec, Canada

institut de Planétologie et d'Astrophysique de Grenoble, Univ. Grenoble Alpes, Grenoble, France

${ }^{j}$ Planetary Science Institute, Tucson, AZ, USA

${ }^{k}$ Space Research Centre, Department of Physics and Astronomy, University of Leicester, Leicester, UK
${ }^{2}$ Applied Physics Laboratory, Johns Hopkins University, Laurel, Maryland, USA ${ }^{m}$ Laboratoire de Géologie de Lyon, Université de Lyon - ENS de Lyon, Lyon, France ${ }^{n}$ Department of Astronomy, Mount Holyoke College, South Hadley, Massachusetts, USA

${ }^{\circ}$ Centre for Planetary Science and Exploration, University of Western Ontario, London, Ontario, Canada

${ }^{p}$ Jet Propulsion Laboratory, California Institute of Technology, Pasadena, CA, USA ${ }^{q}$ Institut d'Astrophysique Spatiale, Université Paris Sud-CNRS, Orsay, France ${ }^{r}$ Niels Bohr Institute, University of Copenhagen, Copenhagen, Denmark ${ }^{s}$ Optical Science Center for Applied Research, Delaware State University, Dover, DE, USA

${ }^{t}$ Commissariat à l'Energie Atomique et Energies Alternatives, DEN, Dept of Phys. Chem., Saclay, France

"Institut des Sciences de la Terre, Univ. Grenoble 1 - CNRS, Grenoble, France ${ }^{v}$ Institute of Meteoritics and Dept of Earth and Planetary Sciences, Univ. of New Mexico, Albuquerque, USA 
the many scientific results: discovery of felsic Noachian crust, first observation of hydrated soil, discovery of manganese-rich coatings and fracture fills indicating strong oxidation potential in Mars' early atmosphere, characterization of soils by grain size, and wide scale mapping of sedimentary strata, conglomerates, and diagenetic materials.

\section{Introduction}

ChemCam is a suite of two analytical instruments: a stand-off Laser Induced Breakdown Spectroscopy (LIBS) system and a Remote Micro-Imager (RMI). In LIBS analysis, a sample is ablated by a pulsed laser; ions, atoms and molecular species are electronically excited in a high-temperature, short-lived plasma. As the plasma cools down, atoms and molecules decay from their excited levels and release energy in the form of light. The light is collected for spectral analysis. The RMI provides context images and documents the accurate location for each laser shot. ChemCam is the first extra-terrestrial use of LIBS, which has been operating on the Mars Science Laboratory (MSL) Curiosity rover since 2012 to determine the composition of Mars rocks and soils at standoff distances. ${ }^{1}$ This paper provides an assessment of ChemCam use and performance on Mars, and describes some lessons learned relative to our expectations prior to launch, ${ }^{2,3}$ with the idea of providing general guidance for future missions.

The ChemCam instrument weighs less than $10 \mathrm{~kg}$. Its laser, telescope, and RMI are located at the top of the remote-sensing mast, while spectrometers and processing unit are in the rover body. ${ }^{2,3}$ It utilizes a passively cooled diode-pumped Nd:KGW laser with two amplifier slabs to produce $5 \mathrm{~ns}$ pulses of $1067 \mathrm{~nm}$ photons with energies up to $35 \mathrm{~mJ}$. The laser system generates a beam that is expanded through a $110 \mathrm{~mm}$ diameter SchmidtCassegrain telescope to produce a focused spot $(<550 \mu \mathrm{m})$ on targets 2 to $7 \mathrm{~m}$ from the telescope, or occasionally at $1.56 \mathrm{~m}$ for the on-board calibration targets. Plasma is created on the target when the laser energy density is above $10 \mathrm{MW} \mathrm{mm}{ }^{-2}$. The same telescope is used to collect the plasma emission, launching it into a $5.75 \mathrm{~m}$ long multimode silica optical fiber leading from the rover's mast to its body. The light is received by a demultiplexer and three spectrometers covering $240-850 \mathrm{~nm}$, except for gaps from 340 to $385 \mathrm{~nm}$ and 469 to $492 \mathrm{~nm}$. The LIBS field-ofview is $0.67 \mathrm{mrad}$. The spectrometers, referred to as UV, violet (VIO), and visible and near-infrared (VNIR), have a relatively simple Czerny-Turner design with resolutions of $\sim 0.049 \mathrm{~nm}$ per pixel (UV), $\sim 0.042 \mathrm{~nm}$ per pixel (VIO), and $\sim 0.21 \mathrm{~nm}$ per pixel (VNIR). They are custom-built spectrometers based on the Ocean Optics Incorporated HR2000 fiber spectrometer design. ${ }^{3}$ The detectors are three E2V 42-10 back illuminated $2048 \times$ 512 pixel CCDs that are operated in a low-noise mode. The spectra are collapsed to $1 \mathrm{D}$, typically binning 200 rows to cover the beam spread. Integration times are approximately $3 \mathrm{~ms}$, longer than the plasma duration, which is on the order of $10 \mu \mathrm{s}$. Therefore it captures some background light that is partly removed when a dark (= no laser) spectrum of the same duration is subtracted. The CCD itself is not gated. Wiens et al. ${ }^{4}$ describe the in-flight performance of the unit. The ChemCam mast-unit also houses the RMI, a high-resolution camera that is

inherited from the ESA Rosetta project. Its field-of-view is $20 \mathrm{mrad}$. It can identify a $1 \mathrm{~mm}$ feature from a $10 \mathrm{~m}$ distance, making it the highest resolution remote sensing imager on Curiosity. Le Mouélic et al. ${ }^{5}$ provide details of its in-flight performance.

Mars rovers must operate robotically at all times due to the long 3-22 light travel times between the Earth and Mars. The MSL rover, also known as Curiosity, typically receives a set of commands at the beginning of its day on Mars, and these commands cover the whole day of operations, or several days on the weekend. Downlinks of data to the Earth are relayed through either the Mars Odyssey or Mars Reconnaissance Orbiter spacecraft, usually at the end of Curiosity's day. The data are received by NASA's Deep Space Network of satellite dishes around the world. ChemCam is operated, on average, between 1 and $2 \mathrm{~h}$ every other Sol (Mars day). ${ }^{6}$

ChemCam was first turned on right after landing, and on Sol 13 of the landed portion of the mission it acquired its first LIBS data on a target named "Coronation". Between Sol 13 and Sol $800, \sim 188000$ LIBS spectra were acquired on $\sim 5800$ points distributed over $\sim 650$ individual targets. In addition, $\sim 3300$ RMI images were acquired (see Table 1 for details). Several months after the end of the nominal mission (Sol 668), on Sols 799 to 801, ChemCam experienced its first anomaly. As the instrument was acquiring standard data, the emission of its continuous wavelength laser, which was used to focus the instrument telescope, started to fade away rapidly. Left without its nominal autofocus capability, the instrument has been operated differently thereafter. The period extending from

Table 1 Summary of ChemCam activities up to Sol 801

Sol range

Working sols

Laser shots

RMI images

LIBS targets

Mars targets

Cal. targets

Blind targets

Individual LIBS points

Targeted rasters

Depth profiles

Blind targets

Calibration targets
$10-801$
419
188126
3321
653
574
10
69
5834
566 activities
4677 points
144610 shots
25 activities
63 points
11250 shots
69 activities
652 points
19560 shots
442 activities
442 points
12706 shots 
landing (Sol 0) to Sol 801 is named by the ChemCam team "Season-1". This paper reports on the use and performance of ChemCam over Season-1 exclusively. Season-2 corresponds to a 6 month period of degraded performance for the focus capability, which was subsequently fully compensated for with complex operational modes. After a number of software upgrades, the initial performance and operational efficiency are restored as of Sol 983, the start of Season-3.

In this paper, we present an overview of the first LIBS experience on another planet. The first section "Analytical capability" summarizes the data processing to provide elemental compositions and target classification, and provides a comprehensive description of the limits of detection, accuracy, and precision that are obtained with ChemCam. The following section "Implementation and operations" covers all aspects of the operations, discussing relative merits of depth profiles, rasters, and other operational tools used to investigate the Martian surface. This is the first time that such a critical assessment is given of the LIBS technique as applied to planetary exploration. The last section "Key findings from elemental composition" presents a bird's-eye view of the many scientific results from ChemCam.

\section{Analytical capability}

In this section we provide the general concepts of data reduction and the actual state of elemental detection and quantification. The rapid pace of scientific discoveries on Mars presented additional challenges to the development of the analytical capability and calibration standards because important discoveries, such as the presence of clays on Mars ${ }^{7-9}$ were made after selection of the instrument by NASA.

\section{Pre-processing and elemental identification}

ChemCam pre-processing is described in the study of Wiens et $a .^{4}$ and is summarized here. Raw data from the deep space network are instantly delivered by the Operational Product Generation System of the MSL Ground Data System. ChemCam LIBS spectra are processed as follows, and in the following order.

Dark removal. For each burst of laser shots, a non-laser background exposure of the same duration is recorded. We call it a "dark" spectrum. It is averaged over several exposures (typically 30) to decrease its intrinsic noise, and is subtracted from each laser-induced spectrum. LIBS pits modify the local albedo. Thus ideally the LIBS spectrum from each laser shot should have a corresponding distinct dark spectrum. However, this is not practical and instead a single dark spectral average is taken before or after the laser burst.

Noise removal. Wavelet transform is used to decompose individual LIBS spectra. ${ }^{\mathbf{1 0}}$ At each wavelet, an estimation of the noise is calculated and a hard thresholding at 3 sigma is applied. The de-noised spectrum is reconstructed.

Continuum subtraction. The continuum under LIBS emission lines is caused by bremsstrahlung and ion-electron recombination. It is extracted using the lower frequencies of the wavelet transform. A fit to the local minima is performed in wavelet space. The technique provides a rapid and efficient way to remove the continuum over the large spectral range of each spectrometer separately. However, when spectral studies are performed over very narrow spectral ranges, often with peak fitting, some additional continuum contributions sometimes need to be removed. The background signal, including the continuum, is distance dependent, so its subtraction partially corrects for distance biases.

Wavelength calibration. A titanium calibration plate onboard Curiosity is used to establish a channel-to-wavelength relationship and to track potential drifts. The Ti spectrum is rich with hundreds of lines in the UV, VIO, and VNIR spectral ranges. The wavelength calibration varies with the spectrometers' temperature, moving by $\sim 4$ pixels over the observed range $\left(-4{ }^{\circ} \mathrm{C}\right.$ to $\left.+30{ }^{\circ} \mathrm{C}\right)$. The final spectra are calibrated to better than 0.2 pixels, which corresponds to $0.01 \mathrm{~nm}$ in the UV. The Ti plate is regularly targeted to verify the wavelength calibration and to track potential instrument change with age.

Counts to photons. Finally, the LIBS signal as recorded by the spectrometers in Digital Numbers (DN) is converted to spectral radiance in phot/shot $/ \mathrm{mm}^{2} / \mathrm{sr} / \mathrm{nm}$ at its source. This conversion accounts for the optical characteristics of the telescope, the analog-to-digital conversion electronics, the spectrometer response function (all of the above calibrated before launch) ${ }^{4}$ and the distance to target in $1 / R^{2}$ (where $R$ is the distance).

Distance effects. The on-target energy density (in $\mathrm{MW} \mathrm{mm}^{-2}$ ) influences plasma conditions. As the distance from the mast increases from $1.56 \mathrm{~m}$ to $7 \mathrm{~m}$, the laser spot size increases from 300 to $550 \mu \mathrm{m}$ diameter. ${ }^{2}$ Therefore, a change in the plasma energy as a function of distance from the mast is expected. However, with the continuum subtraction, the response function in $1 / R^{2}$ above, and a normalization to the total number of counts per spectrometer (after background subtraction), distance effects are removed to first order. The plasma temperature is independent of distance within uncertainty as shown by Wiens et al. ${ }^{4}$ However, there are subtle effects that are emission line specific and need to be taken into consideration as a second order distance correction. These effects affect the intensities of the measured LIBS emission lines and, by and large, can be taken into account by carefully selecting LIBS emission lines acquired from the Martian dust. ${ }^{11}$

Pre-processed spectra yield calibrated atomic/ionic emission lines, which allow element detection and identification. Typically, neutral and first ionized atomic lines are observed, and under the very favorable Martian conditions, occasionally we observe second ionized lines. Accounting for the Mars-tovacuum pressure difference, all LIBS lines detected on Mars are found in the NIST database. The instrument is calibrated to vacuum wavelengths. To facilitate line identification, the ChemCam team has developed its own Martian database, ${ }^{\mathbf{1 2}}$ which is therefore a subset of the NIST library specifically for emission lines typically observed with the ChemCam laser fluence and under Martian ambient pressure. This database and a related visualization tool are accessible with the archived data on NASA's Planetary Data System (PDS). 


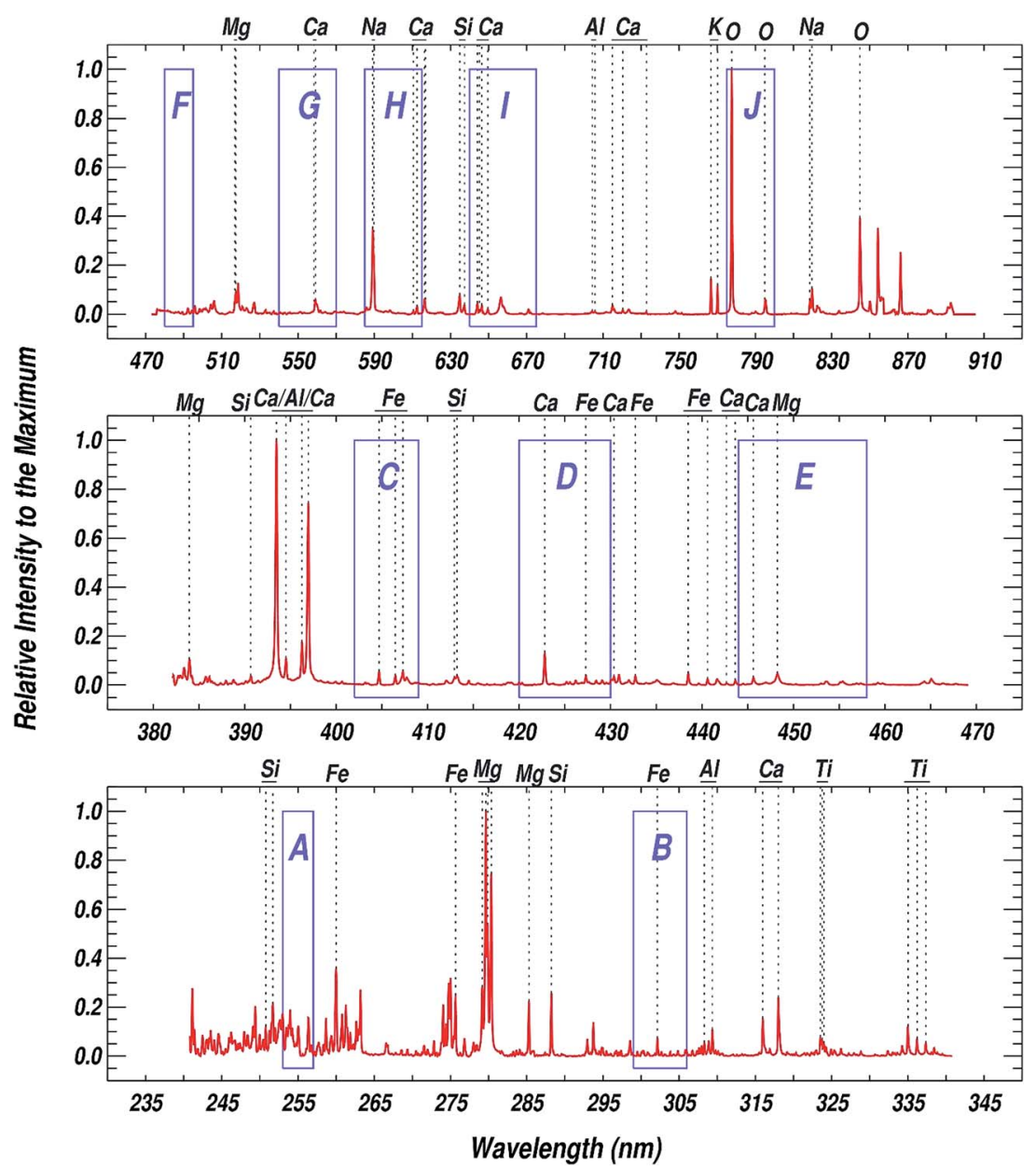

Fig. 1 Overview of major elements detection. Thirty shot average spectrum for "Saline_Valley" (Sol 707). Bottom to top: data from the UV, VIO, and VISIR spectrometers. Wavelengths are along the $x$-axis and count rates along the $y$-axis. Vertical scales are normalized, per spectrometer, to one for clarity. A few peaks for major elements are highlighted. Blue boxes, labeled (A) to (J), correspond to the range of wavelengths for insets in Fig. 2.

Fig. 1 is a standard product from a ChemCam automatic process. For each burst, an average spectrum is generated with noise removal, background subtraction, wavelength calibration, and dark subtraction. A few peaks for major elements are highlighted. Because of their large abundance, a few lines for major elements have high signal-to-noise ratios (typically $>100$ ). Four closely spaced $\mathrm{Mg}$ lines around $279 \mathrm{~nm}$ are the dominant characteristic of the UV range. There are also Ca lines near $316 \mathrm{~nm}$ and a Si peak at $288.24 \mathrm{~nm}$. Half of the peaks in this region are typically from $\mathrm{Fe}$. The series $\mathrm{Ca}-\mathrm{Al}-\mathrm{Al}-\mathrm{Ca}$ around $395 \mathrm{~nm}$ is characteristic of the VIO range. There are approximately half as many VIO peaks as in the UV range. This region is not so dominated by Fe (only $1 / 4$ of the lines). The oxygen peaks around $777 \mathrm{~nm}$ and $845 \mathrm{~nm}$ are characteristic of the VNIR range, as well as the Na doublet at $589 \mathrm{~nm}$. Fig. 2 shows spectral plots over very narrow wavelength ranges for the detection of minor and trace elements. Each spectrum is normalized to the total number of counts per spectrometer. We use two targets as references: "Coronation" (Sol 13), the mafic rock that was ChemCam's first target, and "Ross" (Sol 379), a typical sandstone.
While not expected, in addition to atomic/ionic emission lines, molecular lines have also shown to be diagnostic of elemental composition under certain circumstances. Molecular lines form when atoms recombine in the cooling plasma. In the LIBS analytical field, they are far less studied and used than ionic and atomic transitions. However, recent laboratory studies ${ }^{13-15}$ have opened the path for quantitative analysis and low limits of detection (LoD) from the use of molecular lines.

\section{High-level processing}

Several techniques are part of the ChemCam toolbox for highlevel processing. They depend on various calibration sets of well-known compositions.

The "univariate technique" is straightforward in atomic spectroscopy, and yet provides rapid and useful results. Peak fitting and local adjustments of the continuum are necessary to isolate emission lines of interest and to calculate peak areas. A calibration curve is obtained for the regression between this variable (area or line strength) and known elemental abundances. The univariate technique is particularly adapted to elements that have very few LIBS lines, often the case for trace 

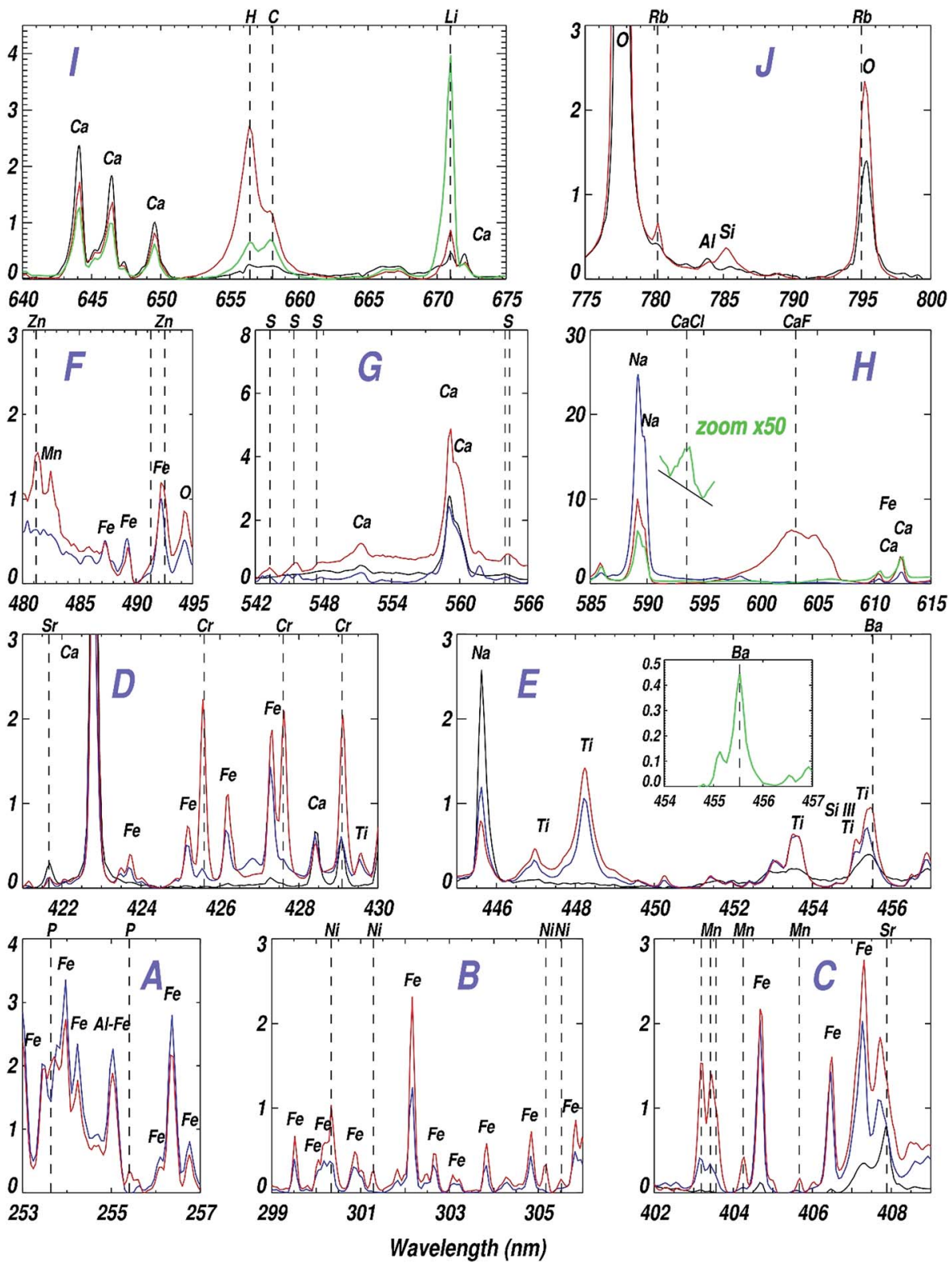

Fig. 2 Spectral focus for the detection of minor and trace elements. Wavelengths are along the $x$-axis and count rates along the $y$-axis. Each spectrum is normalized to the sum of the counts, per spectrometer. For each panel, the black spectrum corresponds to "Ross" (Sol 379) and/or the blue one to "Coronation" (Sol 13). Panel A: detection of P. The red spectrum is for "Epworth \#5" (point 5, Sol 72). Panel B: detection of Ni. Red is "Mammoth \#4" (Sol 758). Panel C: detection of Mn and Sr. Red is "Neil \#7" (Sol 619). Panel D: detection of Sr and Cr. Red is "Copper_Queen \#4" (Sol 746). Panel E: detection of Ba. Red is "Akaitcho \#7" (Sol 50). The zoom in red is "Akaitcho \#7" minus "Coronation" to highlight the Ba peak. Panel F: detection of Zn. Red is "Neil \#7" (Sol 619). Panel G: detection of S. Red is "Cumberland \#3" (Sol 292). Panel H: detection of CaCl and CaF. Red is "Epworth \#5" (Sol 72). Green is "Cumberland \#3" (Sol 292). The zoom (factor $\times 50$ along the $y$-axis) is for "Cumberland \#3" to highlight the molecular line for CaCl. Panel I: detection of H, C, and Li. Red is "Saline_Valley" (Sol 707). Green is "Marquette \#3" (Sol 335). Panel J: detection of $\mathrm{Rb}$. Red is "Starck" (Sol 15).

and minor elements, to some line ratios such as $\mathrm{Al} / \mathrm{Si}$, and occasionally to major elements. ${ }^{16,17}$ It does not account for "matrix effects" (factors that cause line intensity to vary independently of elemental concentration, or possibly from emissions by other elements - see the multivariate techniques described in the next paragraph as a way to overcome this problem) as it discards much information in the spectrum. Univariate calibrations use the normalization to total counts to account for the overall plasma intensity.
Multivariate techniques use the entire spectrum (or a significant portion of it) to develop a regression model. ${ }^{18-22}$ They can be more robust to matrix effects because they use most of the available information. Multivariate methods are much more computationally intensive than the univariate method. They apply very well to major elements, most of which have a large number of strong emission lines over a wide spectral range. Besides the selection of the training set (next paragraph), a couple of parameters are adjustable to optimize the fit for each 
element: the number of components, and spectral normalization. ${ }^{18}$ Two multivariate techniques were used by ChemCam: Partial Least Squares (PLS) regresses multiple spectra (the training set) against a single element at a time (PLS1) or simultaneously against multiple elements (PLS2). It is closely related to the Principal Component Analysis (PCA) technique, which projects the data onto the directions of the largest variance of the data. Independent Component Analysis (ICA) is a blind source separation technique that extracts independent spectral components from a large population of spectra. ICA scores are correlation coefficients for each of the independent components. ICA spectral components have been shown to isolate the emission lines from a single (often major) element very well. ${ }^{22}$ Thus the scores of certain ICA components correlate with the concentrations of elements of interest. ICA scores are normally used for classification, but with the benefit of a very large dataset of spectra from standards of known compositions (next paragraph) we can also derive a correlation between ICA scores and absolute elemental concentrations. Thus ICA is used in our purpose for quantification. Calibration curves were derived for each element by plotting the relevant ICA score against the known composition of targets analyzed in the laboratory. PLS and ICA are not exclusive; there are advantages on both sides. It is even possible to combine the best results from each approach into a more optimized model that matches expected geochemical relationships better. ${ }^{23}$

The success of these techniques depends on the quality of the input database in terms of number of targets and compositional range coverage. There are currently three such databases. The first one consists of spectra collected from ten targets on-board the rover. ${ }^{24,25}$ These targets are intensively used for verification of instrument health, for wavelength calibration, and to support quantification. However, due to their limited number, they do not cover the full range of compositions on Mars. Prior to launch, the science team assembled a collection of 69 geochemical standards, ${ }^{4}$ and obtained spectra with the
ChemCam flight model. The targets were maintained under Mars atmospheric conditions at $3 \mathrm{~m}$ distance. This database helped to drive the first ChemCam quantitative results (up to Sol 1000). An extended lab database of spectra from more than 300 standards, including some pure minerals, has subsequently been acquired with the ChemCam laboratory setup at Los Alamos National Laboratory, at $1.6 \mathrm{~m}$ distance. The larger database includes the complex elemental compositions and diversity observed at Gale crater and permits a more robust quantification. All data from Sol 0 to the present have been re-calibrated with the new database, ${ }^{23}$ and both the Mars data and the calibration database are available on the PDS.

\section{Limits of detection, precision and accuracy}

Most elements can be detected with LIBS in the lab (for a review of LIBS elemental detection capacities, please refer to Cremers and Radziemski ${ }^{26}$ book Appendix C). On Mars, at remote distances, detection depends on their concentration in the first place, but also on possible interferences with other elements. For each element, LODs are determined from laboratory data and our ability to derive a linear correlation, above the noise level, between certified concentrations and a quantity derived from the spectral analysis (peak intensity, ICA scores, or PLS outputs). We find that LODs are highly variable from one element to another, ranging from a few ppm (e.g. $\mathrm{LOD}^{\mathbf{1 7}}$ for $\mathrm{Li}$ is $\sim 20 \mathrm{ppm}$ ) up to a few\% (e.g. $\mathrm{LOD}^{27}$ for $\mathrm{SO}_{3}$ is $>5 \%$ ).

Major elements (O, Na, Mg, Al, Si, K, Ca, Ti, and Fe). These constitute most of the geologic target compositions at percentlevels. They are metals and metallic elements found as oxides and metalloids associated with $\mathrm{O}$ as oxides. As such, they are quantified as oxides, e.g., as $\mathrm{wt} \% \mathrm{SiO}_{2}$, etc., based on the most common oxidation state in geological materials. Each element has from a few diagnostic LIBS lines ( $\mathrm{K}, \mathrm{Al}, \mathrm{Ca}, \mathrm{Na}$ ) to hundreds of lines (Ti, Fe). Fig. 3 is a summary of the compositional ranges of major element oxides measured on Mars, using a global

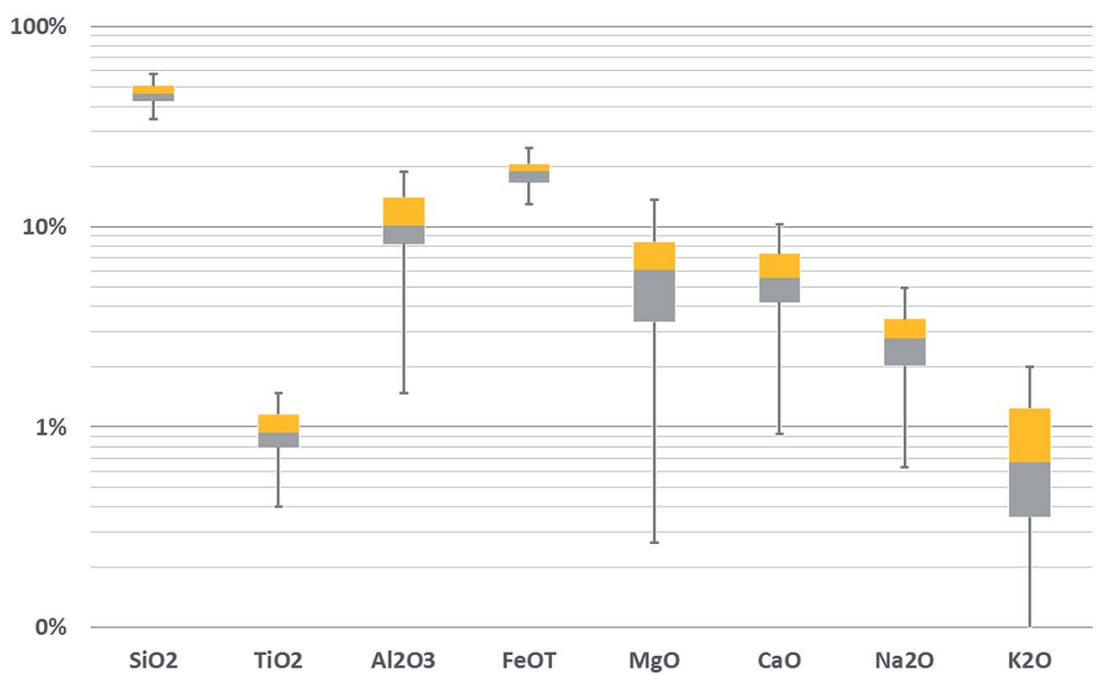

Fig. 3 Composition range for the major oxides, as measured by ChemCam on Mars. Box plot (max whisker length = 1.5; i.e. points or lower than 1.5 times the $25^{\text {th }}$-to $-75^{\text {th }}$ interquartile range are "outliers") from bottom to top: lower adjacent value, $25^{\text {th }}$ percentile, median, $75^{\text {th }}$ percentile, upper adjacent value. 
model that combines ICA regression and sub-model PLS results. ${ }^{23}$ For each box plot, limits from the bottom to top correspond to the lower adjacent value, the $25^{\text {th }}$-percentile, the median, the $75^{\text {th }}$-percentile, and the upper adjacent value. The Whisker length is $\mathbf{1 . 5}$, as it will be for the rest of this publication: points are considered as "outliers" if they are higher or lower than 1.5 times the $25^{\text {th }}$-to- $75^{\text {th }}$ interquartile range. For a normal distribution, such a limit corresponds to $\sim 2.7 \sigma$. This chart shows the wide range of compositions for targets within their Martian context, the mineralogy being dominated by silicates. The sum of all oxides (not shown) has a median of $94.5 \mathrm{wt} \%$, a lower value at $82.3 \mathrm{wt} \%$ and an upper value at $106.7 \mathrm{wt} \%$. Because the sum of all oxides is not constrained to $100 \%$, values above this limit correspond to statistical variations around each oxide modelled composition that are propagated onto the total, or may reveal a composition very different from our reference database or with differing LIBS behavior. The same applies to values below $100 \%$, but this is generally explained by undetectable elements or elements difficult to quantify with LIBS (e.g., $\left.\mathrm{SO}_{3}\right)$.

To estimate the accuracy of the ChemCam predictions, we use the root mean squared error of prediction (RMSEP) from a test set of laboratory samples of known composition. RMSEP is reported on the basis of leave-one-out cross-validation ${ }^{4}$ or $n$-fold cross validation ${ }^{23}$ using the differences between the predicted and known values of each element. The test set for each major element was selected to have a distribution as similar as possible to the full training set used to generate the regression models. The accuracy of predicted compositions varies with composition. For example, the $\mathrm{SiO}_{2} \mathrm{RMSEP}$ is $\sim 4.9 \mathrm{wt} \%$ for well predicted concentrations around $60 \mathrm{wt} \%$. However the technique is less sensitive to low $\mathrm{Si}$ concentrations. Hence, we find an RMSEP of $\sim 7.1 \mathrm{wt} \%$ for concentration of $\mathrm{SiO}_{2}$ around $35 \mathrm{wt} \%$. The reader should refer to Anderson et al. ${ }^{23}$ and future publications for a discussion on the maximum RMSEP values that can be considered for each oxide.

ChemCam precision on homogeneous targets at a constant range, such as on-board calibration targets, is excellent. To estimate the precision, we take the standard deviation of calibration target observations with high signal-to-noise. We obtain a range of precision values for each of the oxides: $\mathrm{SiO}_{2}(0.45-$ $1.91 \mathrm{wt} \%), \mathrm{TiO}_{2}(0.02-0.11 \mathrm{wt} \%), \mathrm{Al}_{2} \mathrm{O}_{3}(0.24-1.74 \mathrm{wt} \%), \mathrm{FeO}_{\mathrm{T}}$ (0.61-1.65 wt\%), $\mathrm{MgO}(0.26-0.66 \mathrm{wt} \%), \mathrm{CaO}(0.45-2.12 \mathrm{wt} \%)$, $\mathrm{Na}_{2} \mathrm{O}(0.10-0.2 \mathrm{wt} \%), \mathrm{K}_{2} \mathrm{O}(0.006-0.28 \mathrm{wt} \%)$. Note that these precision values are for observations on different sols, different rover orientations, and different times of the day. Repeated observations of the same target under identical conditions may show even less variation than the precisions listed here. The results described here complement the precision results given in a more abbreviated form in the study of Blaney et al. ${ }^{\mathbf{2 8}}$ for precision within a raster and from day to day. On unknown targets, the precision is reported as the standard deviation of the abundances derived from a shot-to-shot analysis (typically bursts of 30 shots). As a side note, ChemCam does not appear to have ever shot a Mars target that was translucent or transparent enough to not produce a spark. This likely occurs because the ubiquitous global dust interacts with nearly every surface, facilitating sparking even on very Si-rich rocks.

Non-metallic elements (H, C, O, P, S). Oxygen is included in this list for consistency, but its case cannot be dissociated from other major elements (see above). The amplitudes of the $\mathrm{O}$ emission lines are not necessarily proportional to the amount of $\mathrm{O}$ in the target, because of coupling of the plasma with $\mathrm{CO}_{2}$ in the atmosphere. Generally non-metallic elements are difficult to detect and to quantify, with the exception of $\mathrm{H}^{26}$ in spite of their importance for biogenic-related science. Nitrogen is not in this list: it has been seen in the laboratory for concentrations above $5 \%$, but not yet on Mars.

The hydrogen peak at $656.6 \mathrm{~nm}$ from the Balmer series is the prime indicator for $\mathrm{H}$ detection. It can be deconvolved from the nearby carbon triplet around $658 \mathrm{~nm}$ (Fig. 2, panel I), which is due to the breakdown of the atmospheric carbon dioxide. A lot of care needs to be given to the dark subtraction, because of the Fraunhofer absorption line in the sunlight reflected back from the target. ${ }^{29} \mathrm{H}$ peak intensity varies significantly with target type and chemical group. A ubiquitous strong hydrogen signal is found for dust and soils. ${ }^{30}$ Rocks display medium to low signals depending on their type.

Several carbon lines at $247.9 \mathrm{~nm}$ (CI), $658 \mathrm{~nm}$ (CII) and $833.74 \mathrm{~nm}(\mathrm{CI})$ are detected on all targets analyzed by ChemCam on Mars. This is primarily due to the contribution of the Martian atmosphere $\left(96 \% \mathrm{CO}_{2}\right)$ to the LIBS plasma. When targets with higher carbon contents are analyzed, the intensity and number of detected $\mathrm{C}$ peaks increase to reach a total of $18 \mathrm{C}$ peaks and 21 C2 Swan bandheads in the case of the pure graphite CCCT5 target. $^{31,32}$ Univariate models for carbon detection were generated based on the intensity of those lines and indicated that the limit of detection for carbon was relatively high, around $5 \mathrm{wt} \% .^{31}$ So far in the mission, no ChemCam target has demonstrated levels of carbon line intensity statistically above the variations induced by the Martian atmosphere. In the meantime, the carbon line at $657.8 \mathrm{~nm}$ (Fig. 2, panel I), which interferes with the hydrogen line at $656.3 \mathrm{~nm}$, is routinely analyzed to evaluate a laser coupling proxy in the determination of target hydration with ChemCam.

Phosphorus at geological concentrations is difficult to observe with LIBS. The most intense phosphorus lines in the ChemCam range are around 253 and $255 \mathrm{~nm}$, where Fe signatures dominate (Fig. 2, panel A). There are other lines at $919.3 \mathrm{~nm}$ at the edge of the VNIR spectrometer. Phosphorus has been identified on Mars with ChemCam; ${ }^{33}$ the team is still working at defining an accurate LoD for $\mathrm{P}_{2} \mathrm{O}_{5}$.

Sulfur is difficult too with LIBS, especially with ChemCam because its ionization energy is relatively high and most of the intense $S$ peaks lie outside the range of the spectrometers. ${ }^{34,35}$ Weaker lines at 543.3, 545.4, 547.4 $\mathrm{nm}$, and around $564 \mathrm{~nm}$ are regularly used (Fig. 2, panel G). A preliminary LoD around 5$10 \%$ was obtained for $\mathrm{SO}_{3}$. The detection of $\mathrm{S}$ is particularly important for the identification of calcium sulfates. ${ }^{27}$

Halogens (F and Cl). Fluorine and chlorine are important but difficult to detect. Transitions between various excited states yield $\mathrm{F}$ and $\mathrm{Cl}$ atomic/ionic peaks around $685.6 \mathrm{~nm}$ and $837.6 \mathrm{~nm}$, respectively. Because of low energy levels, only high 
LoD values around $5 \mathrm{wt} \%$ are usually obtained, ${ }^{26}$ which is not well suited for most geological studies. Alternatively, molecular lines form when atoms recombine in the cooling plasma. Most of the observed LIBS molecular emissions on the Earth are oxides for which the ambient air typically supplies the $\mathrm{O}$ atom. ${ }^{36}$

Thanks to the long integration time of the ChemCam spectrometers $(3 \mathrm{~ms})$, molecular emissions of both CaF at $603.1 \mathrm{~nm}$ and $\mathrm{CaCl}$ at $593.5 \mathrm{~nm}$ were observed at Gale crater, ${ }^{37}$ which was the first detection of $\mathrm{F}$ on Mars (Fig. 2, panel H). Experiments performed at Los Alamos National Laboratory (LANL, New Mexico) under Martian conditions yield LoD of $0.2 \mathrm{wt} \%$ for fluorine. Up to Sol 800, about 100 targets exhibit the CaF molecular emission, with some concentrations up to $14 \mathrm{wt} \%$ for F. At such a level, fluorite $\left(\mathrm{CaF}_{2}\right)$ is the most likely trace mineral; in these cases the $\mathrm{F}$ atomic lines are also observed. For chlorine, the molecular emission of $\mathrm{CaCl}$ has been only rarely observed (fewer than 10 cases). In contrast to fluorine, the atomic chlorine line at $837.6 \mathrm{~nm}$ seems to be more frequently observed than that of the CaCl molecular emission. The cause of this discrepancy can perhaps be found in the low Ca concentration of the Cl-bearing samples. Another possible explanation is a preferable recombination of $\mathrm{Cl}$ with $\mathrm{Mg}$, which ChemCam cannot observe in the molecular form because the emission lines are located in the detection gap between the UV and VIO detectors. The few ChemCam observations of $\mathrm{CaCl}$ have been associated with excesses of $\mathrm{Na}$, causing the presence of $\mathrm{NaCl}$ to be suspected.

Minor and trace elements (Li, Rb, Sr, Ba, Cr, Mn, Ni, Zn). These concentrations range from a few ppm to $0.1-1 \mathrm{wt} \%$. Such a large range is reflected in the Relative Standard Deviations (RSDs) of the emission peak areas (highest for the lowest amounts, and lowest RSDs for the highest concentrations). Both the univariate technique and PLS are used to quantify these elements, based on the on-board calibration targets ${ }^{\mathbf{4 1 6 , 2 4 , 2 5}}$ and laboratory sample suites that are custom-made for that purpose.

Lithium is a light lithophile element and is not usually included in geochemical assays because it is not detected by $\mathrm{X}$-ray fluorescence or some other typical assaying techniques. ChemCam provides a rapid quantification of lithium at the ppm level as its (unresolved) doublets at 670 (Fig. 2, panel I) and $812 \mathrm{~nm}$ are very well detected with LIBS. ${ }^{38}$ Several models using PLS and univariate techniques have been tested. The LoD for $\mathrm{Li}$ is around 20 ppm. ${ }^{17}$

Rubidium is rather easy to detect above the oxygen at $777 \mathrm{~nm}$ (Fig. 2, panel J). It has been modelled using a PLS method adapted to a restricted set of emission lines. ${ }^{17}$ The detection limit is $\sim 10 \mathrm{ppm}$ with an accuracy of $\sim 30 \mathrm{ppm}$. $\mathrm{Rb}$ is expected to be present above detection limits in feldspar, mica and clay minerals, and is often detected with ChemCam.

There are several strontium peaks but the one at $421.67 \mathrm{~nm}$ (Fig. 2, panel D) provides the best univariate and PLS calibration curves with low RSDs. ${ }^{16,17}$ The accuracy is $\sim 200$ ppm and LoDs are as low as tens of ppm. Strontium is usually representative of Ca- or K-rich minerals.

Barium is quite difficult to detect. Among several peaks, the main line at $455.5 \mathrm{~nm}$ can be detected down to $100 \mathrm{ppm}$, being careful with interferences with Si III and Ti (Fig. 2, panel E). The best models are obtained with the univariate technique. The accuracy is $\sim 700$ ppm. ${ }^{17}$ The highest values of barium were found in Martian K-feldspars. ${ }^{39,40}$

Chromium is quite difficult to quantify in geological materials with LIBS, because its peaks between 424 and $430 \mathrm{~nm}$ interfere with Fe. The accuracy is around 710 ppm. ${ }^{16}$ However, the detection limit is quite low, down to tens of ppm. A new quantification will be developed using lab standards, with a larger range of concentrations to simulate actual Martian compositions.

Manganese has many LIBS peaks scattered across the ChemCam wavelength range. The 403-404 nm range (Fig. 2, panel D) is relatively free of interferences ${ }^{12}$ and is therefore suited to use for quantification of MnO. A dedicated set of standards ( 0.43 to $76 \mathrm{wt} \% \mathrm{MnO}$ ) was run at LANL. The LoD was found at $\sim 0.06 \mathrm{wt} \% \mathrm{MnO}$. The accuracy scales with the abundances. ${ }^{41}$

Nickel is challenging to detect in geological materials with LIBS. The most important lines are at $301.28 \mathrm{~nm}$, around $305 \mathrm{~nm}$, and at 309.35, 310.27 and $313.5 \mathrm{~nm}$ (Fig. 2, panel B). Ni has so far been observed in only two Mars targets, with detection limits higher than $1000 \mathrm{pm}$.

There are several lines to identify $\mathrm{Zn}$ around 330 and $334 \mathrm{~nm}$. The strong $\mathrm{Zn}$ line at $481.2 \mathrm{~nm}$ (Fig. 2, panel F) is used to identify and quantify $\mathrm{ZnO}$, using a dedicated calibration set of samples enriched in zinc to generate a univariate quantification model. The ChemCam limit of quantification for $\mathrm{ZnO}$ is $3 \mathrm{wt} \%$ (at 95\% confidence level) and $1 \mathrm{wt} \%$ (at 68\% confidence level) and ChemCam's limit of detection is around $0.7 \mathrm{wt} \%{ }^{42}$

\section{Implementation and operations}

Beyond its analytical capability for elemental composition, LIBS as a tool for exploration offers the geochemist several advantages that have been widely discussed in the literature: $\mathbf{1}^{\mathbf{1 4 3 - 4 6}}$ no sample preparation, analysis within its petrological context, dust removal, sub-millimetre scale investigation, multi-point analysis, the ability to carry out statistical surveys, and wholerock analyses, and rapid data acquisition. After $\sim 800$ Sols of intensive MSL operations at Mars, ChemCam can now be used to benchmark the advantages of LIBS for in situ geochemistry (and sometimes mineralogy) on another planet.

To aid the following discussion, a few definitions are given here. A "burst" is a continuous series of laser shots, with ChemCam usually done at $3 \mathrm{~Hz}$, up to 150 shots. A spectrum is registered for each laser shot. All spectra are returned, while returning the average spectrum only is rarely requested. A "point" is a single location on Mars, which is investigated most often by one laser burst or by several laser bursts with no motion of the mast. A "depth profile" is a point analysis using more than 50 and up to 1000 laser shots in order to investigate possible changes of composition with depth. "A raster" is a multi-point investigation following different geometrical arrangements ( $M \times N$, with $M$ and $N$ from 1 to 20). A "target" is a unique rock/soil feature on Mars, which is duly registered with 


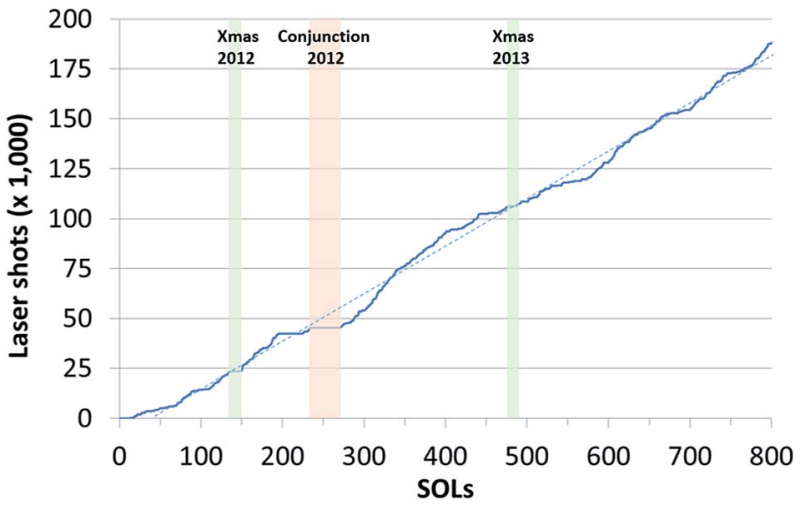

Fig. 4 Cumulative number of laser shots during ChemCam Season-1. The linear fit (dot) has a slope of 238 shots per sol.

its own name by the MSL science team. The same target can be investigated by several rasters or/and individual points.

Table 1 keeps track of the different activities conducted during Season-1: $>5800$ individual points have been interrogated on $>650$ targets with a total of $>180000$ laser shots. Multiple interrogations of the same target are the rule, such as with a raster. ChemCam was operated approximately every other day: on 419 of the first 802 Sols. The imaging capability with the RMI proved to be more useful than expected: $:^{5}$ LIBS points are always documented by one or more RMI images, providing high resolution views of the targets both before and after the laser shots. An additional color Mastcam image is also usually acquired after the LIBS for a broader context. Fig. 4 displays a cumulative histogram of laser shots during Season-1. Periods with no ChemCam activities can be easily spotted; these are mostly Christmas vacations and solar conjunction. Other such times were due to rover flight software updates or an anomaly. After a learning period of approximately 60 Sols, an average rate around 238 shots per sol was reached.

\section{Standoff}

A remote capability is clearly an advantage for planetary exploration. Prior to its delivery, the instrument was tested and qualified to $7 \mathrm{~m}$ - hereafter, unless otherwise specified, for operational purposes, the "distance from ChemCam" is defined from the center of ChemCam's outer face along the telescope optical axis. The minimum distance, excluding calibration targets on the rover deck, is $2.17 \mathrm{~m}$ ("Ritchie", Sol 401). This is essentially the distance from ChemCam's telescope to the ground directly in front of the rover. The maximum distance measured on Mars was $7.45 \mathrm{~m}$ ("Mell", Sol 530) generating useful qualitative results (line identification, classification) but low signal-to-noise for shot-toshot analysis. As an empirical rule, only spectra for targets below $5 \mathrm{~m}$ are used for quantitative studies. Fig. 5 displays the histogram of target distances as acquired by ChemCam. Most targets are shot at relatively close proximity to the rover; the distribution decreases regularly with distance. The primary reason for this trend is the resolution of imagery that is used by scientists to select the targets. Navcam cameras are a pair of monochrome imagers mounted on the rover mast, just below ChemCam. This

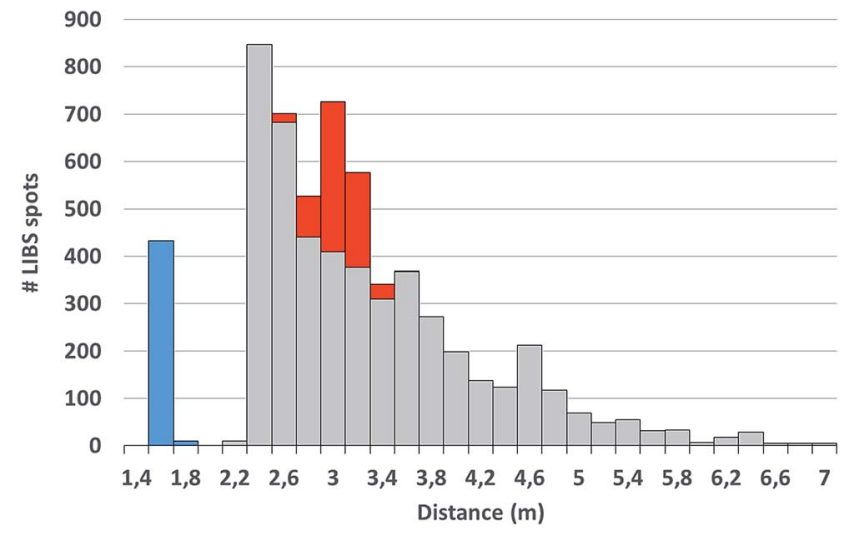

Fig. 5 Histogram of target distances to ChemCam. Two populations are highlighted: blind targets (red) around $3 \mathrm{~m}$, calibration targets (blue) at $\sim 1.56 \mathrm{~m}$.

is the primary tool for target selection; the pixel size at the center of Navcam's field-of-view is $0.82 \mathrm{mrad}$ per pixel. At least 3-4 pixels are generally needed to visualize a feature. Therefore it is difficult to visualize features that are $<5 \mathrm{~mm}$, such as veins, porphyritic rocks, laminae, etc. Hence the resolution of images that are used for pointing and shooting the laser seems to bias the choice of ChemCam targets. Small targets are also harder to hit further away. The science team also recognized that signal-to-noise is better at a close distance, influencing their choice. Thus, half of the targets are below $3 \mathrm{~m}$, and $95 \%$ below $5 \mathrm{~m}$. The population between 2.1 and $2.5 \mathrm{~m}$ is particularly important because it coincides with the arm work zone (a $80 \mathrm{~cm}$ diam. cylinder, $\sim 1 \mathrm{~m}$ in front of the rover), where ChemCam is used to document the context of contact and drill science. Targets at $1.56 \mathrm{~m}$ correspond to the calibration targets that are mounted at the rear of the rover. There is also a "surplus" of targets around $3 \mathrm{~m}$ because of a ChemCam blind mode: on certain sols, in the absence of Navcam context images for target selection following a rover drive, a fixed position at $\sim 3 \mathrm{~m}, \mathrm{AZ}=90^{\circ}$ (right side of the rover), was automatically targeted during Season-1, mostly along traverses, for a statistical survey of the soils and other surface materials. ${ }^{47}$

Fig. 6 shows the ChemCam targets projected on the ground. Because of the mast position near the front right corner of the rover deck and the implicit distance bias described above, most ChemCam targets are located in front of the rover and to its right. The maximum distance to the intersection of the mast with the ground is $\sim 7 \mathrm{~m}$. Besides, at the end of each drive, a specific mosaic of ChemCam targetable region is taken (Navcam $5 \times 1$ stereo) in front of the rover, introducing further a bias in the distribution of ChemCam targets. While ChemCam is a quick analysis instrument (see below), only $\sim 1$ to 5 targets are sampled per sol when the instrument is ON, which is not sufficient to survey the entire surroundings. Thus scientists need to make the best use of Navcam images to pick ChemCam targets to optimize the representativity of their sampling.

Curiosity's mast pointing capability is key to the success of ChemCam investigations. We find the actual pointing accuracy to be within $\pm 2 \mathrm{mrad}$, as an end-to-end budget that includes uncertainties in azimuth (AZ) and elevation (EL) motors and 


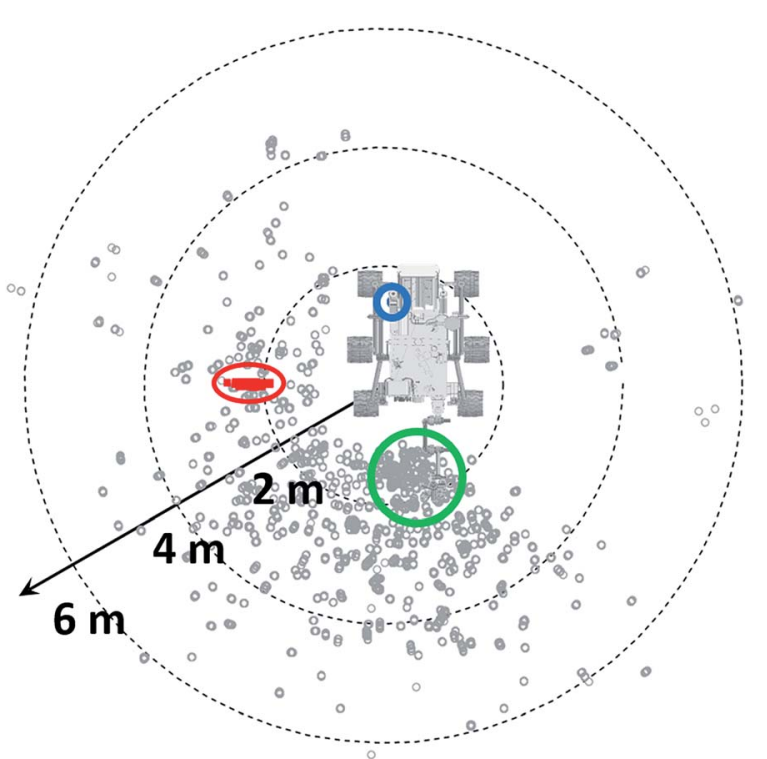

Fig. 6 Distribution of LIBS targets around the rover. The origin of distance is at the nadir of the Remote Sensing Mast (RSM). Blind targets are circled in red, the calibration targets are located in blue and the green circle represents the arm work zone.

associated coding devices, camera models, projection errors, and registration of the Navcam images. This is $\sim 3$ times better than the stated requirements. This excellent performance has allowed us to target very small features on Mars, as shown in Fig. 7, such as inside a $1.6 \mathrm{~cm}$ - diameter hole that was created by the rover's drill (panel a) or at various sub-mm size structures (panels b-d). To make sure that some features below $1 \mathrm{mrad}$ could be targeted, the ability to perform small AZ/EL increments is very important: $\pm 0.5 \mathrm{mrad}$ is regularly achieved. Panel b shows a very closely spaced raster performed to investigate a several-mm-wide transition zone. A repeatability of $\sim 0.5 \mathrm{mrad}$ was also measured in the best case, allowing the science team to target very small veins, but sometimes after repeating different types of rasters over a few sols. Using $2 \mathrm{D}$ rasters often provides the best opportunity to interrogate a vein, such as that presented in panel c. Because the images available for targeting are not always high resolution as mentioned above (especially when the rover moves every day and the images that can be downlinked for planning are limited), sometimes successful pointing on the smallest geological targets is somewhat fortuitous.

\section{Flexibility and adaptability}

ChemCam is a very versatile instrument, with the result that it is somewhat complex to operate. Many different configurations have been tested as the team converged toward using a few operational modes. With regard to the laser itself, several parameters can be adjusted, ${ }^{2}$ including its repetition rate, beam intensity, and the number of laser shots per burst. The repetition rate ranges from 1 to $10 \mathrm{~Hz}$. We found no noticeable relationship between this repetition rate and ChemCam analytical performance. Faster is better in terms of rover resources (to shorten ChemCam activities)
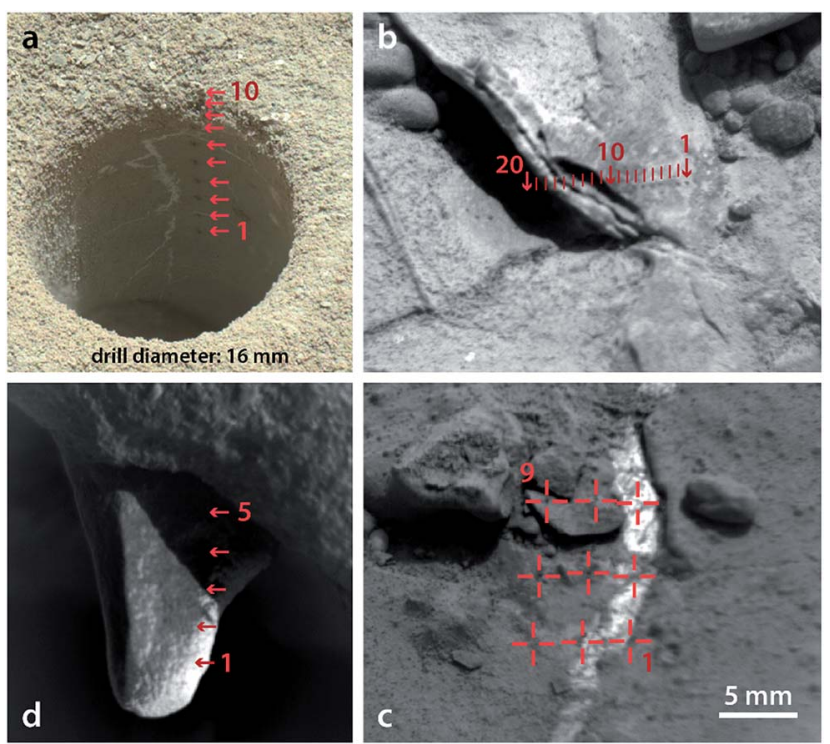

Fig. 7 Pointing capability and ChemCam rasters: (a) MAHLI image of "John Klein" $1.6 \mathrm{~cm}$-diameter drill hole, Sol 270; LIBS markings (red arrows) appear on the hole wall. (b) "McGrath", $1 \times 20$ raster, Sol 226; (c) "Takurak", 3 × 3 raster, Sol 165; (d) "Deep Kill", $5 \times 1$ raster, Sol 443 . Images (b)-(d) have the same scale, shown in (c). Images: NASA/JPLCaltech/MSSS, NASA/JPL-Caltech/LANL/CNES/IRAP/IAS/LPGN/ CNRS/LGLyon/Planet-Terre.

but $3 \mathrm{~Hz}$ was finally decided on to avoid thermal constraints on the laser. A burst of 30 shots takes 10 seconds instead of the minimum of 3 seconds, not a noticeable difference when focusing, imaging, and laser warm-up are factored in. The energy output is controlled by the input current delivered to the laser amplifiers, with choices of $40 \mathrm{~A}$ ( $56 \%$ of the energy on target that is deposited at $95 \mathrm{~A}), 60 \mathrm{~A}$ $(71 \%), 80 \mathrm{~A}(87 \%)$, and $95 \mathrm{~A}(100 \%$, nominal mode). More energy is better in LIBS, but the drawback is to sometimes saturate emission lines. Saturation corresponds to $16300 \mathrm{DN}$ on the spectrometer analog-to-digital converters. At nominal output power $(14 \mathrm{~mJ}$ on target, driven by $95 \mathrm{~A}$ ) we found saturation at up to $3 \mathrm{~m}$ target distances for $\mathrm{Mg}$ (quadruplet of lines between 279.635 and 280.353 $\mathrm{nm}), \mathrm{O}(777.408,777.630)$, Ca (393.477 and 396.774), and $\mathrm{Na}$ $(589.158,589.756)$. This situation is troublesome as the maxima of those peaks were lost. Lowering the input current to $60 \mathrm{~A}(\sim 10 \mathrm{~mJ}$ on target) at target distances below $3 \mathrm{~m}$ did indeed allow measurements of the full dynamic ranges of the peaks and was used regularly up to Sol 400 . While avoiding saturation, this yielded additional matrix effects as the energy to build up the plasma temperature was drastically different as a function of distance. So, thereafter, $95 \mathrm{~A}$ has been used for all targets, with the understanding that only the highest portion of the peak is missing and the peak area is not affected by more than $10 \%$ of its full-height value. However, what is true for geological targets is not for calibration targets, where too many lines are saturated and where saturation accounts for a large fraction of the peak area when shot at this energy level. Thus, calibration targets were shot mostly at 40 A as shown in Table 1, and at $95 \mathrm{~A}$. High level processing was then used to develop dedicated calibration curves at $40 \mathrm{~A}$ or to mask saturated lines. All spectra are checked for peak saturation and the data are culled from the PDS if saturation is observed. 
Another important parameter is the number of laser shots per burst. The relevant question is: what is the number of laser shots that would be necessary to effectively minimize Poisson or shot noise? Shot noise is intrinsic to photon counting experiments and can only be reduced by increasing the number of collected photons, in contrast to systematic errors that may be corrected by other means (see the section on Pre-processing). ChemCam laser shots per burst can be adjusted from 1 to 150 . As a test case, 14 bursts of 30 shots were used on "Jake-M" (Sols 45-48) and treated as independent variables; they are randomly mixed as a collection of 420 individual spectra. Counts under the strong $\mathrm{Na}$ line at $819.7 \mathrm{~nm}$ are accumulated over 5 pixels. We have explored successively the possibility of acquiring $\mathrm{N}$ spectra with $\mathrm{N}$ varying from 1 to 30 . For each value of $\mathrm{N}, 420 / \mathrm{N}$ groups of $\mathrm{N}$ line intensity values were studied, from which total counts could be extracted. From the $420 / \mathrm{N}$ groups, the mean and Relative Standard Deviation (RSD) of the total counts were calculated. The RSD decreases as 1 over the square root of the number of counts as expected, to even out around 6\% RSD after 20 shots. Many other targets, other lines, and other random arrangements have been tested for the same result: a stable RSD between $4 \%$ and $8 \%$ after 20 shots (Table 1). Since the first few shots $(<5)$ are typically imprinted by the signature of the dust, ${ }^{32}$ the ChemCam science team has recommended that, when possible, all points are to use 30 shots to acquire sufficient statistics with margin, when building mean spectra.

Beyond the number of laser shots, most of ChemCam's flexibility comes from the geometrical arrangements of laser points. Ever since they were validated on Sol 19, rasters have been used extensively to target very fine features (veins, concretion nodules, vugs, laminae, cross-beddings, etc.) and to cover the heterogeneity of a target. Thus we have performed 547 1D or $2 \mathrm{D}$ rasters out of 566 activities (Table 1) for a variety of geometries: $1 \times 3,1 \times 5$ ( $33 \%$ of the activities), $1 \times 6,1 \times 8,1 \times$ $10(21 \%), 1 \times 15,1 \times 20,2 \times 5,2 \times 2,3 \times 3(33 \%)$. Very long ones, such as $1 \times 20$, have been executed across various sedimentary strata. Large rasters, such as $4 \times 4$ and $5 \times 5$ increase statistics for comparison with data from the Alpha Particle X-ray Spectrometer (APXS) instrument mounted on the rover arm, for instance. Larger rasters are desired by the science team, but available resources often push the tactical team back to smaller sizes. In general $1 \times 5$ and $3 \times 3$ are the most frequently used rasters, being good compromises between better ground coverage and longer duration. We also did $1 \times 3,1 \times 4,1 \times 5$, $1 \times 6$, and $2 \times 2$ rasters for depth profiles and $1 \times 5,1 \times 10$, and $1 \times 20$ rasters for blind targeting.

\section{Small scale and sample heterogeneity}

Prior to the delivery of ChemCam, several series of shots on a black-anodized Al plate were performed at different distances under Mars atmospheric conditions ${ }^{2}$ to conclude that the ablated area varies from $350 \mu \mathrm{m}$ to $550 \mu \mathrm{m}$ from 2 to $7 \mathrm{~m}$, respectively. We take advantage of the superior resolution of the MAHLI instrument, the high resolution color imager at the end of Curiosity's arm, to check this value on Mars. We used several rasters on "Stephen" (Sols 611, 620,630) that show especially clear laser impact pits (Fig. 8) because the target is unusually shiny and smooth. ${ }^{41}$ The surface is also clear of dust after a few shots. The image resolution is $\sim 30 \mu \mathrm{m}$ per pixel. The target is $2.29 \mathrm{~m}$ from ChemCam, and only centimetres from MAHLI when the image was taken afterwards. Each laser fingerprint is fit to an ellipse whose aspect ratio corresponds to the $43^{\circ}$ viewing angle from the ChemCam telescope. For the series of 30 shots (6 points) we find the fingerprint regions are $509 \pm 32 \mu \mathrm{m}$ diameter, for 150 shots ( 3 points) they are $559 \pm 36 \mu \mathrm{m}$ and for the 600 shots (series of 4 consecutive 150 -shot bursts) it is

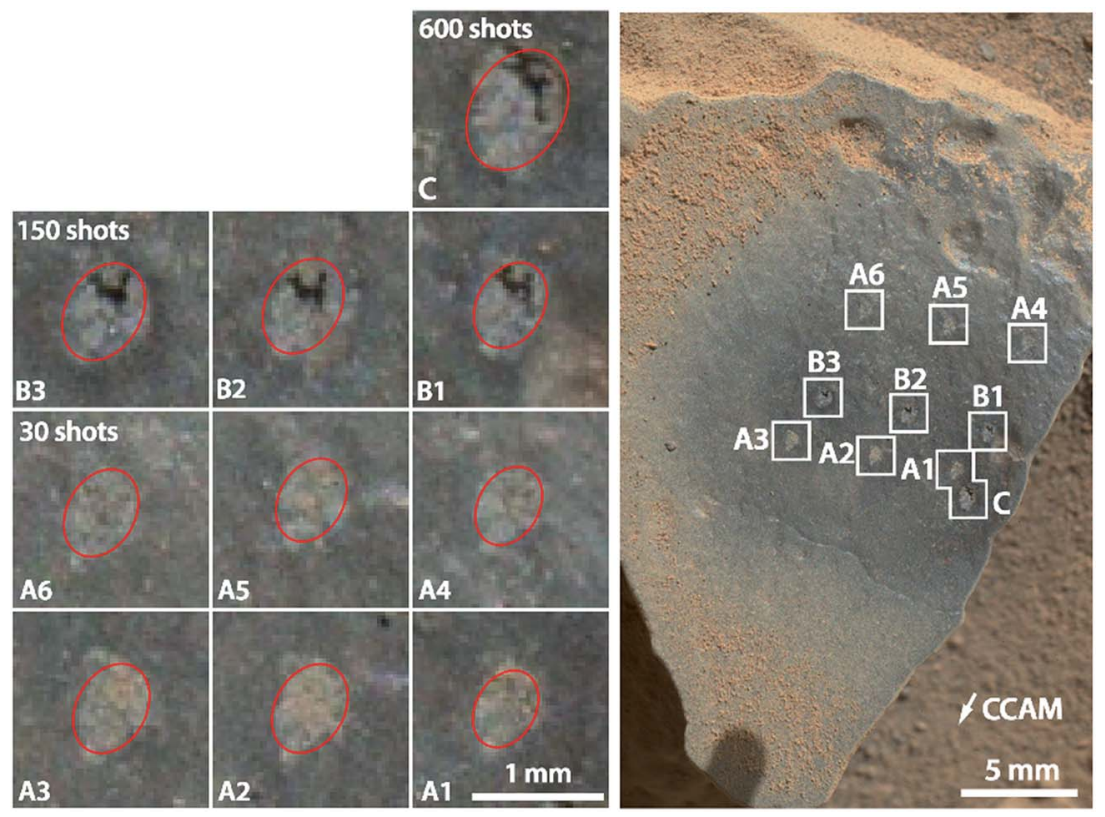

Fig. 8 Various series of laser shots on "Stephen" (Sol 611-620-630) from a MAHLI image on Sol 672. The red ellipses indicate a manual estimate of the impact area. The dashed line outlines the area that has been cleared of dust. Images: NASA/JPL-Caltech/MSSS. 

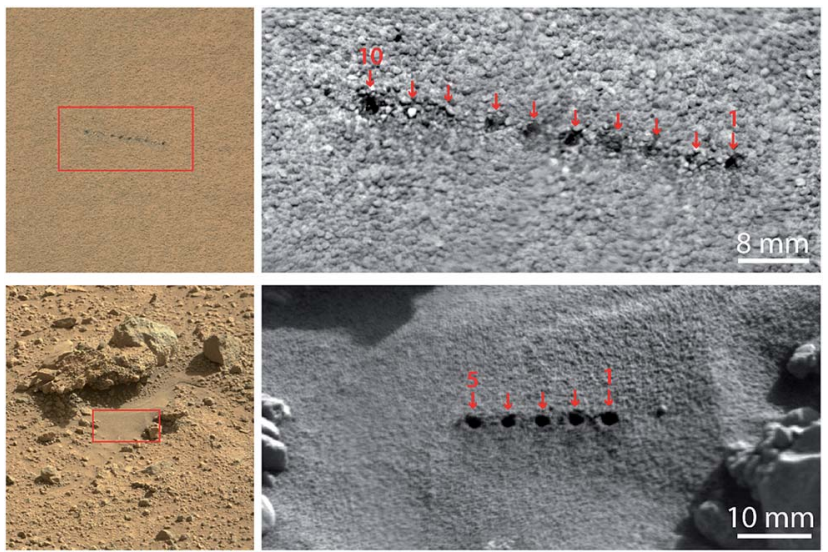

Fig. 9 ChemCam shots on coarse soils (top panel, "Holts_Ledge", $1 \times$ 10 raster, Sol 669) and fine soils (bottom panel, "Sandy Dam", $1 \times 5$ raster, Sol 544). Context images from Mastcam. Images: NASA/JPLCaltech/MSSS; NASA/JPL-Caltech/LANL/CNES/IRAP/IAS/LPGN/ CNRS/LGLyon/Planet-Terre.

$749 \mu \mathrm{m}$. Those diameters correspond to areas that have been clearly modified by the laser impact. They are upper values for the laser pits themselves. This result is consistent with what was measured in the laboratory on a very simple plane surface. It is likely that the increased size observed on Mars is due to micromotion (slight wobbling) of the rover and its mast. The duration over which the 30 shots were fired is 10 seconds. However, for 600 shots, which require several 150-shot bursts, the duration is $>3$ minutes. Thus the larger spot size may be largely due to additional motion of the mast over this longer duration. This effect can be checked by using the acquisition of several RMI images interbedded with laser shots.

Measuring pit diameters in soils is much easier, since they are readily observable in RMI images (Fig. 9). In fine soils, crater edges are very sharp. For 201 separate bursts of 30 shots on soils, the median crater diameter is at $1.2 \mathrm{~mm}$, with a range from 0.7 to $1.9 \mathrm{~mm}$ that is probably due to varying grain sizes (Fig. 10). In the laboratory, prior to launch, Wiens et al. ${ }^{3}$ reported on experiments at Mars ambient pressure in a finegrained soil simulant using JDo-1 (73\% of this standard has grain sizes $<20 \mu \mathrm{m})$. The hole produced by the flight instrument was $1.4 \mathrm{~mm}$ in diameter after 50 pulses and $1.8 \mathrm{~mm}$ after 150 pulses. Mars data are consistent with these results.

\section{Dust removal}

Dust is ubiquitous on Mars and this is illustrated by ChemCam. Of $>5000$ points interrogated with LIBS during Season-1, in more than $99 \%$ of the cases, the first few shots show chemical evidence of dust. The only exception is when the same spot is interrogated twice, a few minutes apart. Thirteen sols after landing, the first shots on the on-board calibration targets already exhibit evidence of dust. Even if the target was cleared of dust (see below), dust was again detected by the LIBS when it was interrogated a few sols later. ${ }^{42}$ Individual moving dust grains could even be seen on different RMI images of the calibration targets.

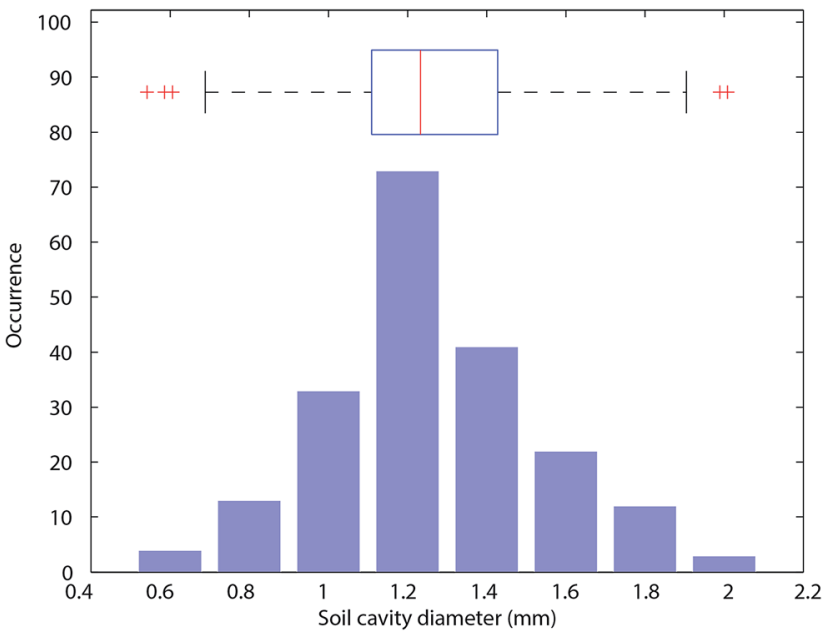

Fig. 10 Histogram of soil cavity (surface area diameter in $\mathrm{mm}$ ) from 201 bursts of 30 shots. Box plot ( $\max$ whisker length $=1.5$ ) from bottom to top (in $\mathrm{mm}$ ): lower adjacent value $=0.69,25^{\text {th }}$ percentile $=$ 1.11 , median $(\mathrm{red})=1.23,75^{\text {th }}$ percentile $=1.42$, upper adjacent value $=$ 1.90, and red crosses for outliers.

Dust can be blown away by the LIBS impact shock wave well beyond the 350-550 $\mu \mathrm{m}$ diameter of the LIBS crater. There are numerous cases of dust removal in the Season-1 ChemCam dataset as shown by the difference between two RMI images before and after the LIBS shots. There were 135 cases of rock targets studied for 30-shot bursts. Independent of the local geometry, the dust-free area is found to be nearly circular around the LIBS pit. There is no apparent dependence of the dust-free diameter on target distance. Fig. 11 is a histogram of dust-free diameters (in $\mathrm{mm}$ ): the median value is $7.5 \mathrm{~mm}$ with a significant dispersion between $6.2 \mathrm{~mm}$ and $9.0 \mathrm{~mm}$ from the $1^{\text {st }}$ to $3^{\text {rd }}$ quartile. The variation is likely due to surface

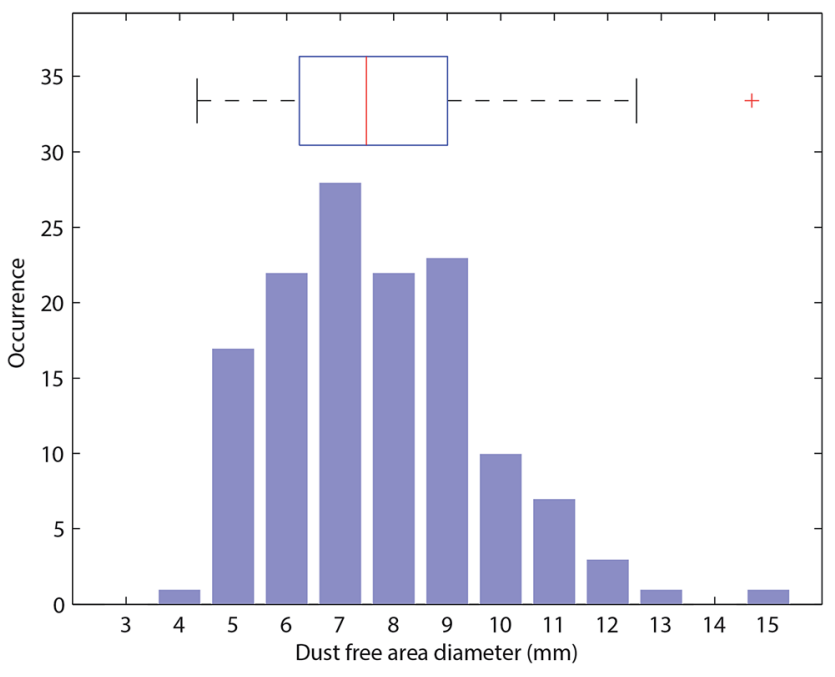

Fig. 11 Histogram of dust free area (diameter in $\mathrm{mm}$ ) from 135 bursts of 30 shots. Box plot ( $\max$ whisker length $=1.5$ ) from right to left to top (in $\mathrm{mm}$ ): $\min =4.3,25^{\text {th }}$ percentile $=6.2$, median $(\mathrm{red})=7.5,75^{\mathrm{th}}$ percentile $=9.0$, upper adjacent value $=12.5$, and red crosses for outliers. 

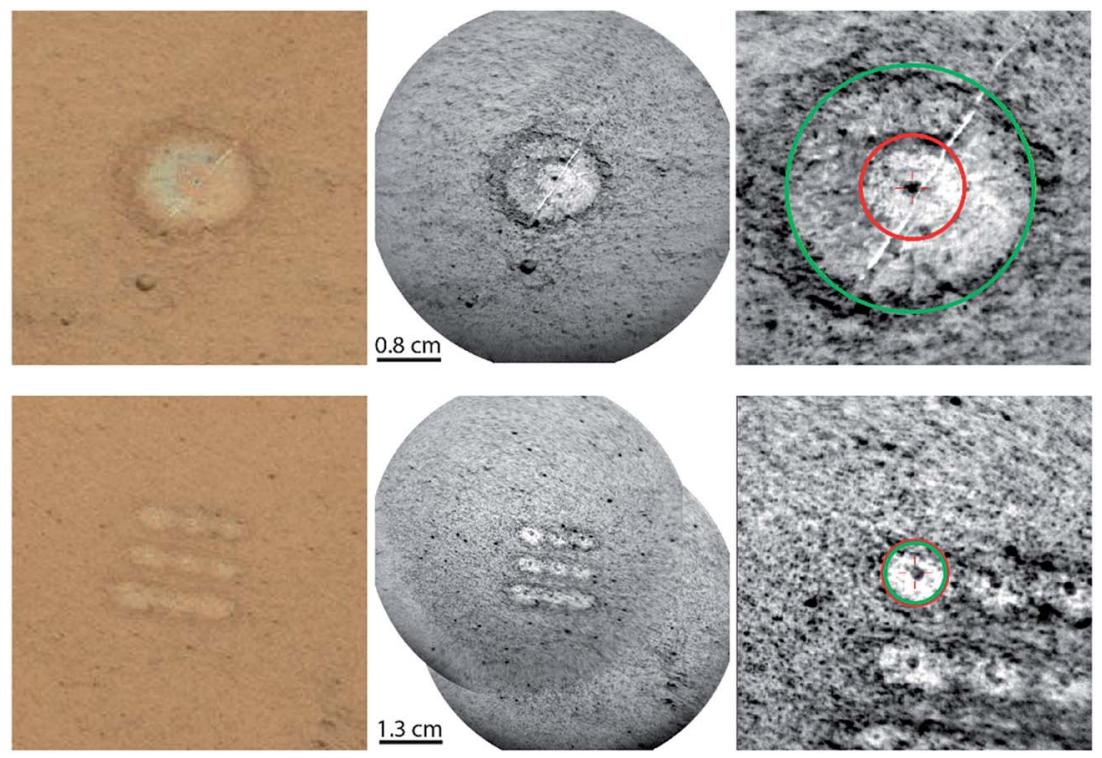

Fig. 12 Dust removal: "Cockscomb" (single point, 150 shots, Sol 773) and "Hanaupah" (3 33 raster, 30 shots, Sol 779). The left panel is a Mastcam context image. The right panel is a zoom of the middle RMI image. On the right panel, the red circle is $5 \mathrm{~mm}$ diameter. The green circle diameter is the area clear of dust: $11.9 \mathrm{~mm}$ for "Cockscomb" and $4.9 \mathrm{~mm}$ for "Hanaupah". Images: NASA/JPL-Caltech/MSSS, NASA/JPL-Caltech/LANL/ CNES/IRAP/IAS/LPGN/CNRS/LGLyon/Planet-Terre.

roughness, its coupling efficiency with the laser beam, slope, and (obviously) the amount of original dust cover. Areas as small as $4 \mathrm{~mm}$ or up to $12 \mathrm{~mm}$ diameter have been observed. Fig. 12 (top) shows an area that has been cleared by 150 laser shots. The area over which dust is cleared is slightly larger than with only 30 shots (bottom). When performing depth profiles, four bursts of 150 shots are usually used with no motion of the mast. From eight depth profiles, we obtain a range for dust-free diameters from 10.0 to $15.2 \mathrm{~mm}$, with a maximum value at 17.8 $\mathrm{mm}$. This is therefore, as expected intuitively, larger than for 30 shots, as illustrated in Fig. 13.

When performing rasters with appropriate spacing between laser pits, the dust free area can be enhanced. Fig. 14 (right) is

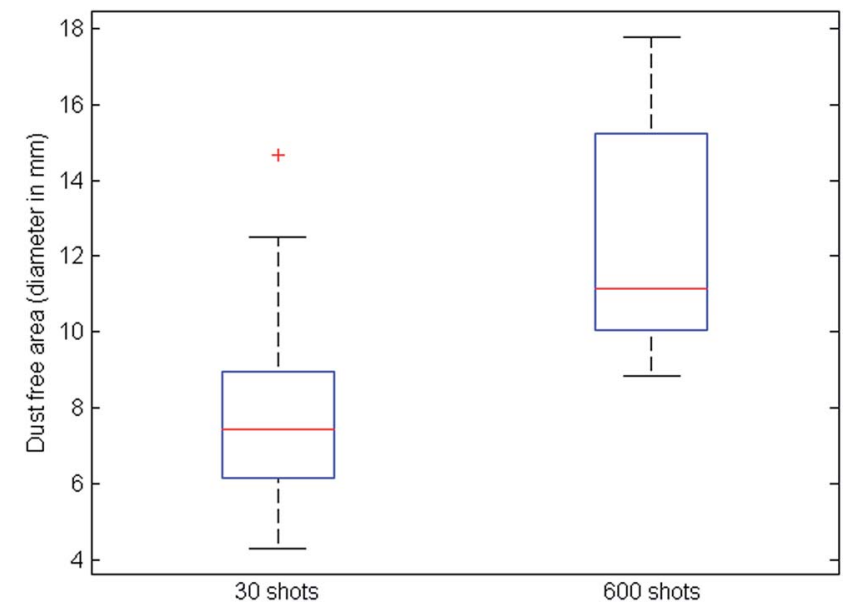

Fig. 13 Dust free area (diameter in $\mathrm{mm}$ ) for 30 shot bursts (135 points) and 600 shot depth profiles ( 8 points). Box plots ( $\max$ whisker length $=$ 1.5 ) for 600 shots from bottom to top (in $\mathrm{mm}$ ): $\min =8.8,25^{\text {th }}$ percentile $=10.0$, median $=11.1,75^{\text {th }}$ percentile $=15.2, \max =17.8$. an example of two consecutive $1 \times 10$ rasters that had removed dust along more than $10 \mathrm{~cm}$ for a width of $1 \mathrm{~cm}$. For 2D rasters, dust-free areas of several $\mathrm{cm}^{2}$ were obtained. Typically, the dust free area has a $\sim 1 \mathrm{~cm}$ diameter after a $3 \times 3$ raster (Fig. 14 left). On a target like "Stephen" (Sols 611, 620, and 630, Fig. 8), with a combination of different rasters, more than $2 \mathrm{~cm}^{2}$ were cleared of dust. The dust-free areas can provide better views of target characteristics in later imaging.

\section{Depth profiling}

For each laser shot, nanograms of material are ablated when the distinctive craters are formed. ${ }^{36}$ In general, nanosecond IR laser pulses generate craters with blobs of melt material on their edges. The ablation process is noticeably less efficient than with
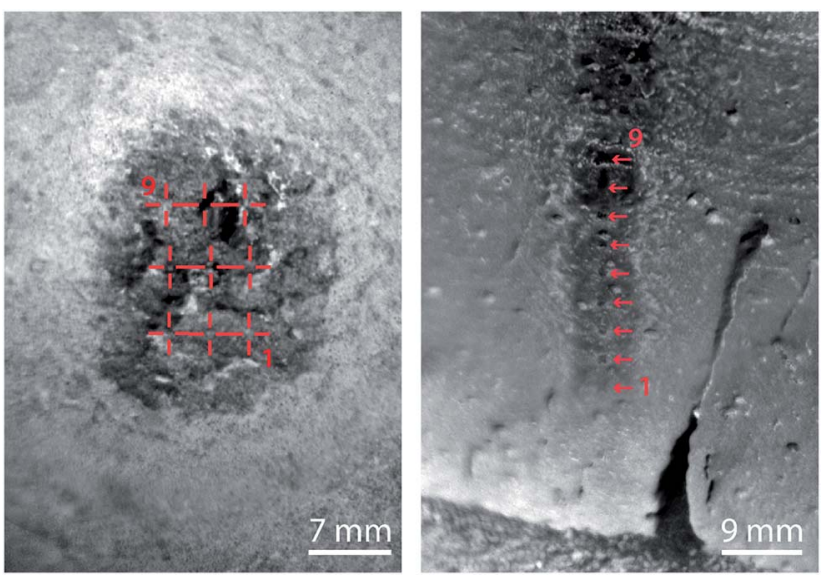

Fig. 14 Dust removal from rasters: "Liga3", raster $3 \times 3$, Sol 601 (left) "Rocknest_3", raster $1 \times 10$, Sol 84 (right). Images: NASA/JPL-Caltech/ LANL/CNES/IRAP/IAS/LPGN/CNRS/LGLyon/Planet-Terre. 


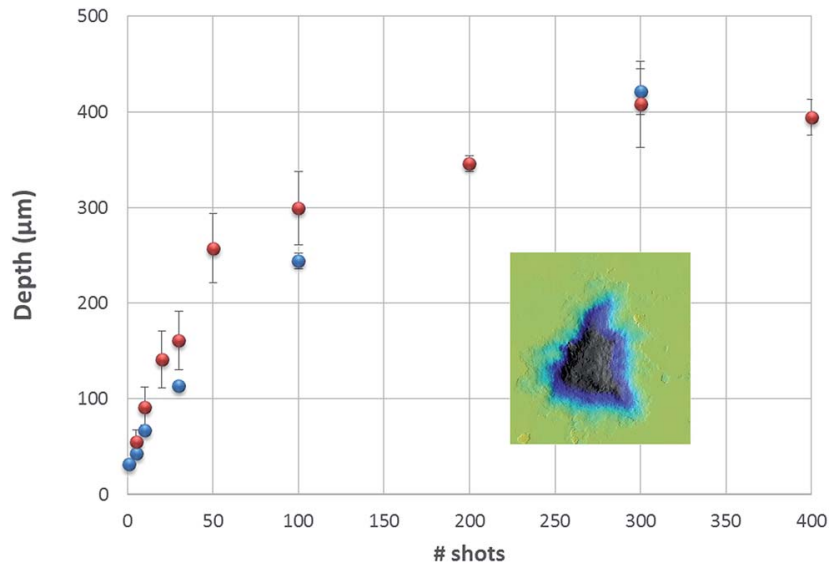

Fig. 15 Depth of LIBS impact crater as a function of the number of shots, for two types of target: a dolomite (red) and compact Mars soil simulant (blue). The data point at the far right is for 900 laser shots. As an inset a crater elevation pattern for 300 shots on the Mars soil simulant.

femtosecond UV lasers. Under Martian conditions, the ablation process is somewhat more effective than at terrestrial ambient pressure. ${ }^{48}$ A recurrent question is how deep LIBS impacts can penetrate a geological target. A systematic study of crater depth with the number of laser shots is outside the scope of this manuscript, as many parameters control the laser-matter interaction: the laser beam characteristics; the target density, crystallinity, thermal and electrical properties that govern the coupling with the beam electric field and the associated heat dissipation. However, a small example is given below.

A few measurements from the laboratory setup at the Institut de Recherche en Astrophysique et Planétologie (IRAP, Toulouse, France) provide insights into the general processes that occur on Mars. We used the ChemCam Mast-Unit qualification model, a $\mathrm{CO}_{2}$ pressure-controlled chamber at $\sim 0.7 \mathrm{kPa}$ and $3 \mathrm{~m}$ standoff distance. The instrument is cooled to $-10{ }^{\circ} \mathrm{C}$. Except for firing through windows in the Martian chamber and the thermal chamber containing the instrument, the configuration is as close as possible to ChemCam at Gale crater. Two targets have been used: a pressed Mars soil simulant (JSC-1) and a dolomite-cemented sandstone from the Grand Canyon. For this study, both targets are considered soft on a geological hardness scale, leading to relatively large maximum depths of penetration. On each one, series of multiple shots were repeated three times. The depth was measured by a calibrated microscope. Fig. 15 displays the depth of penetration as a function of the number of shots for both targets. The profiles are very similar: a high ablation rate at first $(\sim 5 \mu \mathrm{m}$ per shot $)$ transitions to a very low rate $(\sim 0.6 \mu \mathrm{m}$ per shot $)$ after $\sim 100$ shots. A maximum depth around $400 \mu \mathrm{m}$ is reached. A spectral signal is recorded at this depth, which means that while ablation occurs, the hole gets re-filled by the ablated material from the walls. Using the flight instrument, Wiens et al. ${ }^{3}$ obtained a nearly 50\% larger depth of penetration for dolomite, but a much shallower depth for basalt. Differences between these two sets of measurements may well correspond to variations in the cementation of the dolomites/sandstones and the porosity of the basalts. There are two explanations for the maximum depth: an extreme confinement of the plasma and a lower coupling to the material that has been previously ablated and partially melted. Cousin et al. ${ }^{12}$ further explored how LIBS spectra behave with depth, with the conclusion that the SNR is not clearly dependent on the depth or laser energy. The full width at half maximum (FWHM) values of emission lines are constant with depth in rock but can broaden significantly in holes made in soils, due presumably to saturation and self-absorption of the plasma even at Martian ambient pressures. $^{3}$

The ChemCam setup at IRAP was also adapted for soil studies. We used a Mars simulant (JSC-1) that had been sieved to different maximum grain sizes. We report here on results for the $40-80 \mu \mathrm{m}$ range (Fig. 16, left). As shown, the craters are $\sim 2 \mathrm{~mm}$ in diameter, which is close to the upper bound of soil
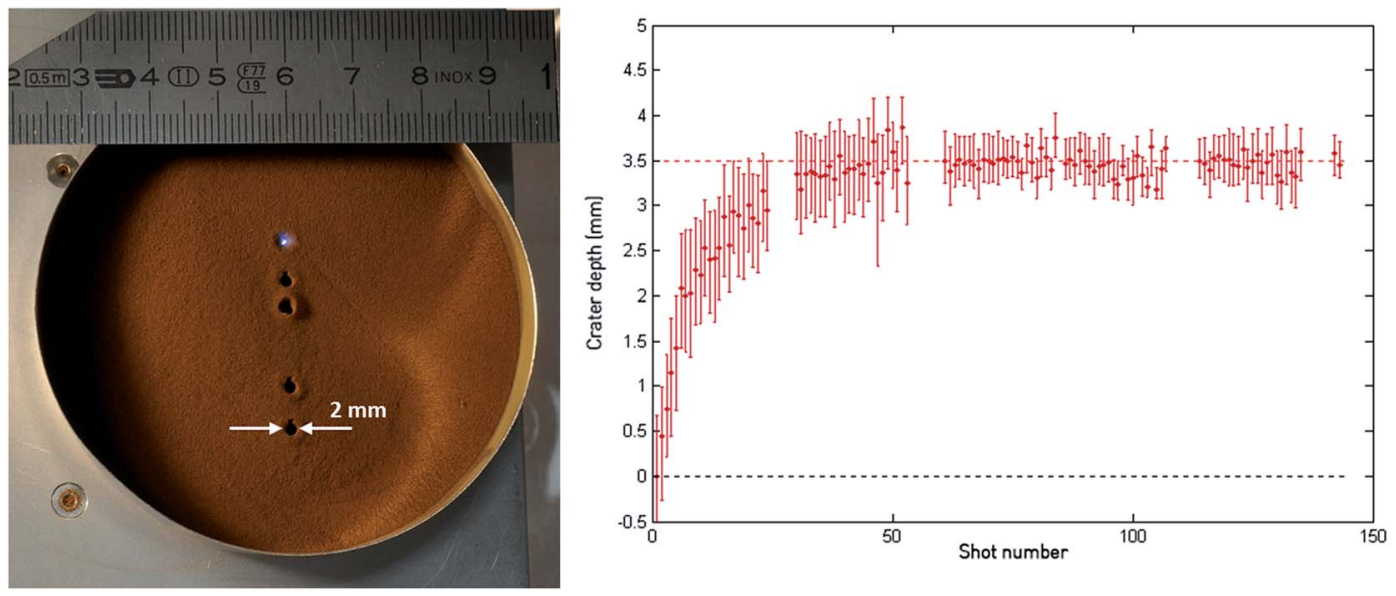

Fig. 16 Measurements in the laboratory of crater diameter and depth in a JSC-1 Mars soil simulant that was sieved to produce layers of thickness between 40 and $80 \mu \mathrm{m}$. Data were acquired at $6.7 \mathrm{mbar}$ of $\mathrm{CO}_{2}$ at $3 \mathrm{~m}$ distance. The laser is run at $1 \mathrm{~Hz}$. The bright spot on the left panel is that of a real LIBS plasma. On the right panel, measurement of crater depth for 150 shots. The error bars represent the size of the luminous primary plasma measured on each image and used to locate the crater depth. 
craters observed on Mars that are indeed coarser than the simulant. For a series of 150 shots, the depth was measured optically and is reported in Fig. 16, right. The LIBS shock wave excavates rapidly with the initial shots. After 50 shots, the max depth $\sim 3.5 \mathrm{~mm}$ is reached, which is $1.5 \times$ the crater diameter. The bright spot on Fig. 16 is that of a real LIBS plasma, deep in the soil crater, where coupling becomes more difficult, and grains fall down the hole.

\section{Rapid measurement}

Acquiring a LIBS plasma takes a few ms and thus a burst goes as fast as the repetition rate of the laser. However, in a complex experiment such as ChemCam, a significant overhead has to be taken into account for the actual duration of a typical LIBS analysis (here defined as a burst of 30 shots). From ChemCam activity templates, we find that a $3 \times 3$ raster of 30 shots, i.e. nine analyses, has a duration of $40 \mathrm{~min}$ : $11 \mathrm{~min}$ to turn the instrument $\mathrm{ON}$ and warm up the lasers at a controlled rate; $22 \mathrm{~min}$ to acquire the LIBS spectra plus four autofocus routines (one on each row plus one for the final image) and two context images, mast motion, data processing and transfer to the rover; 7 min to cool down the lasers and turn the instrument OFF. A $1 \times 5$ raster (including two RMIs and two autofocus) takes $30 \mathrm{~min}$, a $1 \times 20$ raster (incl. 5 RMIs and 8 autofocus) an hour. Many other combinations are possible, often with several rasters sharing the same ON/OFF sequence. The uplink team adjusts the number of images and autofocus routines as a function of the EL/AZ spacing within the rasters and the geometric shape of the target. As a guideline, averaged across a raster, it takes for ChemCam between 3 and 6 minutes to perform a LIBS analysis (single point) with context images.

\section{Key findings from elemental composition}

In this review, we have assembled most of ChemCam original results into a few topics that utilize major element composition as a framework for the geological setting and often minor and trace elements as markers of evolution and alteration. As part of an integrated payload, the ChemCam results are supported by images from the Mastcam and MAHLI imagers, by chemistry and mineralogy from SAM and CheMin onboard laboratories, and by organic and volatile chemistry from the Sample Analysis on Mars (SAM) instrument, mineralogy from the CheMin X-ray diffraction instrument, and by chemistry from APXS. The importance of RMI images for the interpretation of elemental composition, as shown below, also proved to be significant.

\section{Igneous compositions}

Curiosity encountered a variety of igneous rocks showing an ever increasing diversity in composition..$^{39,40,49,50}$ Igneous rocks observed to the west of the Yellowknife Bay (YKB) sedimentary formation are float rocks or clasts in conglomerates. ChemCam textural and compositional analyses led to the identification of 53 massive (non-layered) igneous targets, ${ }^{\mathbf{3 9 , 4 0}}$ both intrusive and effusive, with mafic or felsic samples, the latter dominated by feldspar minerals. From the morphology, color, grain size, patina and chemistry, at least five different groups have been identified, which fit in general into two distinct geochemical series: ${ }^{\mathbf{4 0 , 5 1}}$ (i) an alkali-suite: basanite, gabbro trachy-andesite and trachyte, including porphyritic and aphyric members; (ii) quartz-normative intrusives close to granodioritic composition. All of these observations are geochemically consistent with differentiation of liquids produced by low degrees of partial melting of the primitive Martian mantle. ${ }^{52}$ The latter rock-type (ii) is unlike anything proposed in the literature for Mars but has similarities to the TTG Archean rock suites encountered on the Earth that are related to the building of continental crust. ${ }^{40}$ The bulk composition of igneous rocks observed at Gale, with $\mathrm{SiO}_{2}$ reaching $67 \mathrm{wt} \%$ and $\mathrm{Na}_{2} \mathrm{O}+\mathrm{K}_{2} \mathrm{O}$ reaching $14 \mathrm{wt} \%$, greatly extends the magmatic diversity that was observed by previous landers and rovers. Mars Exploration Rover Spirit found alkalirich compositions in the Noachian terrain at Columbia Hills, but those rocks were basaltic (tephrite and trachy basalts) and they did not exhibit visible feldspar phenocrysts. ${ }^{53}$ At Gale, felsic rocks were observed mainly in the "hummocky plains" near the landing site, and as part of the alluvial fan.

With these observations, ChemCam data provide the first in situ detection of low-density leucocratic igneous rocks on Mars. Sautter et $a l .{ }^{\mathbf{4 0}}$ argued that such felsic rocks are a likely feature of a major fraction of the southern highlands. If so, Gale's felsic rocks would solve the density paradox raised recently ${ }^{54}$ between relatively high values for the crust predicted from SNC meteorites and the vast majority of orbital observation, and a lower crustal density deduced by geophysics (geoid to topography ratio).

\section{Soil analysis}

Prior to ChemCam, the smallest analytical footprint to study chemistry or mineralogy on the surface of Mars was the $3.8 \mathrm{~cm}$ footprint of APXS on MER ${ }^{55}$ and the footprint of the Mössbauer spectrometer on the same missions was $1.5 \mathrm{~cm} .{ }^{56}$ ChemCam therefore provided a reduction in the analytical footprint diameter of $\sim 100 \times$, allowing individual mineral grains to be observed for the first time.

ChemCam found that the soils (the loose and unconsolidated components of the regolith) analyzed at Gale crater have a bulk composition similar to that observed in other locations on Mars $^{57}$ but with local variations and original signatures resulting from the mixing of particles with different sizes and compositions. Three classes of pebbles and coarse grains $(>500 \mu \mathrm{m})$ have been identified in Gale: a felsic group, enriched in $\mathrm{SiO}_{2}, \mathrm{Al}_{2} \mathrm{O}_{3}$, and alkalis, a basaltic group, and a group characterized by a lower $\mathrm{SiO}_{2}$ content. The former shares the same composition and origin as the felsic rocks and conglomerates observed near the landing site, and seems to originate from the Gale crater walls, or from the local weathering of those rocks. The two other groups do not have a clear origin, because they have a different composition from all the rocks observed so far at Gale. The similarity of the third group with the fines suggests they could be aggregates of fines, or that they could be their precursor. $^{47}$ 
Fine-grained particles have a close-to-basaltic composition centered between plagioclase and mafic end-members. They are consistent with the presence of plagioclase, olivine, augite, pigeonite, and some alkali feldspars revealed by CheMin, ${ }^{58}$ but with lower $\mathrm{SiO}_{2}$ content than the larger particles. Overall, the composition of the fine particles is quite homogeneous and lacks an obvious spatial trend with either depth or location. This chemical homogeneity and the presence of olivine ${ }^{58}$ suggest limited or isochemical aqueous alteration. ChemCam has seen varying proportions of $\mathrm{a} \mathrm{SiO}_{2}$-poor, volatile-rich phase, hinting at the presence of a significant content of constituents whose concentrations are not currently estimated by ChemCam $\left(\mathrm{SO}_{3}, \mathrm{H}_{2} \mathrm{O}, \mathrm{P}_{2} \mathrm{O}_{5}, \mathrm{Cl}\right.$, etc. $)$. This phase is likely related to the X-ray amorphous component observed by CheMin. ${ }^{59}$ This is consistent with multiple studies from previous missions, ${ }^{60}$ showing that Martian soils have a composition different from all the rocks analyzed so far. Therefore the question of their origin remains open.

One of the early results from ChemCam is the first detection of Li in Martian materials, especially soils. ${ }^{17} \mathrm{Li}$ abundances are generally low ( $<15 \mathrm{ppm})$. The abundance of $\mathrm{Li}$ provides a test of the sources of fluid mobile elements in the soils, including sulfur and chlorine, which have been known since Viking. ${ }^{61}$ Models for the origin of these mobile elements in the soils include volcanic aerosols and hydrothermal fluids. ${ }^{62}$ The lack of enrichment of the present soils in $\mathrm{Li}$, which is highly fluid-mobile, is consistent with the limited influx of subsurface ground waters, or neutral chloride hydrothermal fluids. These results do not exclude a role for volcanic aerosols or acid sulfate fluids, both of which involve vapor transport, where $\mathrm{Li}$ is immobile. Some of the diagenetic effects noted recently in the mission may also be consistent with acid sulfate processes.

The submillimeter scale of ChemCam analyses and ChemCam's ability to retrieve profiles of chemical composition to depths of $\sim 4 \mathrm{~mm}$ in fine-grained soils are particularly suited to the analysis of processes involved in the genesis of the Martian soils. The presence of this volatile-rich amorphous component is responsible for the large hydrogen signal observed by ChemCam in soils, and this hydration likely accounts for an important fraction of the global hydration of the surface seen by previous orbital measurements. ${ }^{63}$ In the end, comparison between daytime and nighttime soil measurements, however, even at the coldest time of the year, does not show any significant difference, suggesting that this hydration signature does not mostly come from the presence of adsorbed water. This is in spite of some high relative humidity observations by the REMS instrument at some times of the year and locations. ${ }^{64}$

\section{Aeolian dust analysis}

The first LIBS spectrum acquired on Mars (Sol 13) was that of dust. Ever since, at least the first shot of every burst is mixed with a dust signature, except when the same target is shot twice within less than a day. ChemCam data on single-element calibration targets were used to retrieve and analyze in detail the chemical composition of the mobile aeolian dust $(<2-3 \mu \mathrm{m})$ deposited on its surface. The first spectrum of a burst acquired on a graphite calibration target ${ }^{4}$ clearly presents all of the major elements (Fe, $\mathrm{Si}, \mathrm{Mg}, \mathrm{Al}, \mathrm{Ca}, \mathrm{Ti}$ ) that are typically absent from a dust-free graphite spectrum. ${ }^{32}$ The comparison between the first and last spectrum of a burst yields the chemical composition of the dust layer on the target, assuming no $\mathrm{C}$ is present other than the atmospheric contribution. The procedure is repeated on a titanium plate ${ }^{4}$ ( $\mathrm{Ti} \sim 96 \%, \mathrm{Al}$, and traces of $\mathrm{V}$ ), which is routinely sampled to assess the instrument health and wavelength calibration. The dust spectrum is the same through the first 800 Sols of the mission. Dust spectra show a compositional relationship to typical soils analyzed at Gale crater. Spectral line ratios are consistent with a basaltic composition similar to the one detected globally on the planet. ${ }^{30,60,65,66}$ In greater detail, comparison between the dust component and typical fine soils such as "Crestaurum" (Sol 89) indicates a similar content in $\mathrm{Fe}, \mathrm{Mg}, \mathrm{Si}, \mathrm{Ti}, \mathrm{Al}$, and $\mathrm{H}$, but a higher content in $\mathrm{Ca}$ and $\mathrm{K}$. Quantification of the major elements reinforces their similarity to the fine soil composition. ${ }^{30,47}$ The minor elements that were detected (Ba, Sr, Rb, Li, H, Mn, Cr) are within the range of the composition from soil surveys, but exhibit a higher concentration of Li. Every ChemCam first shot presents a strong $\mathrm{H}$ line, indicating that dust is a contributor to the $\mathrm{H}$ content of the Martian samples, which was also detected by the SAM and CheMin instruments. ${ }^{58,65}$ This in turn means that fine dust also contains part of the hydrated amorphous phase reported by CheMin in the soils. ${ }^{32}$ This hydrated dust cover measured in situ is consistent with the global infrared water absorption band seen in orbital data. ${ }^{67}$

\section{Conglomerates}

Conglomerates are rocks composed of grains that are cemented together, from sand-size grains $(<1 \mathrm{~mm})$ to pebbles up to $10 \mathrm{~cm}$ or more. Pebbles often display locally significant rounding and local imbrications that demonstrate a fluvial origin. Conglomerates were observed for the first time on Mars by the Curiosity rover shortly after landing. ${ }^{68}$ The clasts contained in them likely came from Gale crater's rim, transported via watersheds such as the Peace Vallis. ${ }^{6}$ ChemCam has analyzed $\sim 40$ conglomerate targets along the rover traverse, starting at Bradbury landing site in the first month of the mission. ${ }^{68,70-72}$ RMI images of conglomerates display a variety of grains with various tones, from light to dark, including pebbles with white, obviously igneous minerals visible as phenocrysts. The capability of ChemCam to sample individual minerals when larger than the laser beam size $(>0.5 \mathrm{~mm})$ is a powerful analytical tool on this kind of rock. Conglomerates predominantly incorporate igneous clasts, enabling ChemCam to analyze a chemistry representative of the source rocks.

The chemistry of conglomerates can be split into two major chemical groups. First, conglomerates from the hummocky plains and the outcrop named Darwin (Sol 390) are enhanced in felsic components (higher $\mathrm{Si}, \mathrm{Al}, \mathrm{Na}$ and $\mathrm{K}$ ) compared to the average crust composition. ${ }^{71}$ This chemistry suggests a strong contribution of the felsic crust identified from the analysis of 
leucocratic clasts. ${ }^{39,40}$ The analysis of individual grains suggests a plagioclase-dominated mineralogy with the contribution of mafic minerals, local alkali feldspars, and micas. ${ }^{37,71}$ Second, conglomerates found in the vicinity of the Kimberley outcrop (Sol 572) display much higher $\mathrm{K}$ abundance and relatively high Fe content as well, compared to the average Martian crust and the first conglomerate type. This property suggests a genetic link with the potassic sandstones and mudstones observed at the Kimberley outcrop. ${ }^{73}$

\section{Ca-sulfate detection}

Since early in the mission ChemCam has reported numerous Ca-enhancements associated with the detection of sulfur peaks. These points are also depleted in other major elements ( $\mathrm{Si}, \mathrm{Fe}$, $\mathrm{Mg}, \mathrm{Al}, \mathrm{Na}, \mathrm{K}, \mathrm{Ti}$ ), apart from $\mathrm{O}$. This indicates a calcium sulfate phase. ${ }^{74}$ The RMI images show that the Ca-sulfate signatures correspond to a light-toned material, in contrast with the surrounding sediment. ${ }^{74}$ The majority of these light-toned Ca-sulfate targets are elongated veins, and occasionally subspherical nodules, and polygonal (nodular) texture. The latter texture raises a question about the hydration state of the Ca-sulfate analyzed. Calcium sulfates can be found on the Earth in three different hydration states: gypsum, with two water molecules; bassanite, with one water molecule per two Ca-sulfate molecules; and an anhydrous form, anhydrite. An enterolithic texture suggests anhydrite or bassanite (see " $\mathrm{H}$ detection and hydration" paragraph hereafter). These interpretations are in agreement with analyses performed by other Curiosity instruments, for example at $\mathrm{YKB}$. There $\mathrm{CaSO}_{4}$ was identified $^{75}$ by APXS (Alpha Particle X-ray Spectrometer) in the "Rapitan" target that ChemCam also analyzed. Anhydrite and bassanite were also detected by CheMin (Chemistry and Mineralogy) in the first drilled samples. ${ }^{76}$ Finally, Mastcam observations were consistent with the presence of gypsum in multiple locations, ${ }^{77}$ as well as, on various locations, of other phases such as bassanite and/or anhydrite.

Along the traverse, ChemCam first reported Ca-sulfate circa Sol 113, when entering the YKB formation. Since leaving the YKB formation, and up to the $\sim 10 \mathrm{~km}$ point of the traverse at the Pahrump Hills area around Sol 750, ChemCam identified more than $34 \mathrm{Ca}$-sulfate targets. Along the traverse, ChemCam analyzed an extensive boxwork of bright veins that also display a Ca-sulfate composition, ${ }^{27}$ the texture of which is under investigation. ${ }^{78}$ Among all these detections, Ca-sulfates mostly appear as veins, crossing into the sediment as a fracture-filled material. They are thus interpreted as having formed by a fluid event or events subsequent to the local sediment deposition. The occurrence of Ca-sulfate veins is not distributed uniformly through the entire Curiosity path but remains persistent: no other diagenetic feature has been reported so widespread along the traverse. ${ }^{79}$ Moreover, the Ca-sulfate veins cross other diagenetic features (such as nodules at the YKB formation, and cluster-like features at Pahrump Hills). ${ }^{27,80}$ This suggests the occurrence of a late, quite-widespread precipitation of sulfates from groundwater. Ca-sulfates suggest relatively mildly acidic formation conditions compared to $\mathrm{Mg}$ - and Fe-sulfates that appear to be more widespread on Mars as detected from orbital observations.

\section{Chemical survey of sedimentary rocks}

Along the path of the rover from the Bradbury landing site to Sol 800 , ChemCam has sampled various chemistries ${ }^{\mathbf{8 1}}$ that can be summarized as follows for sedimentary rocks. After traversing several hundred meters across the pebble and conglomeraterich Bradbury Rise, Curiosity arrived in YKB. The first outcrop surveyed at Rocknest showed strong enrichment in $\mathrm{Fe}$ and depletions in Mg. ${ }^{28}$ This may be a hint of what Curiosity will find when it reaches the Hematite Ridge. ${ }^{82}$ After leaving Rocknest, Curiosity reached the lowest point in its traverse, the Sheepbed area in the YKB formation (Sols 126-300), which is essentially composed of mudstone. Curiosity performed its first drill sampling at this location. The mudstone shows a very homogeneous composition, close to the average Martian crust. ${ }^{71,75}$ The nearby Shaler fluvial sandstone outcrop (Sols 306-325), the first outcrop of potential deltaic foreset beds (alternation of recessive and resistant sandstone strata), shows $\mathrm{K}$ enrichment. ${ }^{83}$ This enrichment is even more important at the Kimberley formation (Sols 576-632 another drill site flanked by foreset beds), located $7 \mathrm{~km} \mathrm{SW}$ of Shaler, with up to $5.3 \mathrm{wt} \%$ $\mathrm{K}_{2} \mathrm{O}$ on average for the Mount Remarkable member. ${ }^{73}$ Although it is outside the scope of this review, it can be noted that ChemCam subsequently probed the Murray unit at the Pahrump (Sols 801-919) and Marias_Pass (Sols 992-1072) locations. This unit represents the first observed material of $\mathrm{Mt}$ Sharp's base, and shows a very diverse composition, including areas highly enriched in $\mathrm{SiO}_{2}(75-85 \mathrm{wt} \%)$ and $\mathrm{TiO}_{2}$, suggesting a stronger alteration. Curiosity drilled its $7^{\text {th }}$ sampling hole near this high $\mathrm{SiO}_{2}$ area. Overall, ChemCam has observed a wide variety of compositions in sedimentary rocks that comes in addition to the diversity reported for igneous rocks, implying a multiplicity of sources, and of alteration and diagenesis processes.

\section{$H$ detection and hydration}

ChemCam has a unique sensitivity to hydrogen at a submillimeter scale. The hydration of dust has already been discussed above. In rocks, soils, veins, drill holes and tailings, ChemCam found a $\mathrm{H}$ signal in most of the targets along the rover traverse, revealing hydrated materials to different degrees. ${ }^{29}$ The highest hydrogen signal from rocks is mostly found in calcium sulfate formations $^{74}$ and mudstones. The latter observation is consistent with the fluvio-lacustrine mineralogy found by the CheMin instrument in the mudstone drill tailings indicating the presence of hydrated $\mathbf{M g}$-smectites ${ }^{76}$ and hydrated iron oxides expected in the amorphous phase. ${ }^{84}$ Although several studies highlight physical and chemical LIBS matrix effects specific to hydrogen, ${ }^{29,85}$ a normalization of the hydrogen signal was found to correct for most of the effects in a range applicable for the majority of the data acquired on Mars. Applied to the calcium sulfates targeted on Mars, the calibration reveals a hydrogen signal consistent with around $6 \mathrm{wt} \% \mathrm{H}_{2} \mathrm{O}$ content. This corresponds to the presence of bassanite $2 \mathrm{CaSO}_{4} \cdot \mathrm{H}_{2} \mathrm{O}$ but not 
gypsum $\mathrm{CaSO}_{4} \cdot 2 \mathrm{H}_{2} \mathrm{O}$ or anhydrite $\mathrm{CaSO}_{4}$. Bassanite likely originates from the dehydration of gypsum which implies relatively low temperature fluid evaporation from gypsum ${ }^{86}$ and that later desiccating conditions occurred. This recent work demonstrates that the ChemCam hydrogen signal could be used not only to detect but to constrain the water content within fine target features at remote distances. The calibration of the $\mathrm{H}$ LIBS signal remains a challenge because many sources of variability have been identified, but further experiments are being performed to help expand the calibration to target types other than calcium sulfates.

\section{Manganese detection and consequences}

Elevated abundances of Mn have been observed by ChemCam along Curiosity's traverse in Gale crater. In the first 360 Sols of the mission, $\sim 3 \%$ of rock targets analyzed by ChemCam contained Mn abundances that were at least three times the average Martian basalt value of $0.4 \mathrm{wt} \% \mathrm{MnO}$ based on previous in situ measurements, ${ }^{57}$ suggesting the presence of a high-Mn mineral phase. ${ }^{41}$ One target named Caribou (observed on Sol 342) had a single analysis location containing $\mathrm{MnO}$ in excess of $60 \mathrm{wt} \%$, the highest observed on Mars to date. ${ }^{41}$ Not all of the high-Mn observations have a clear geological context (e.g., mineral grains, or a depositional environment), but in at least one location it appears that Mn concentrations occur primarily as Mn-oxide veins that fill fractures within a sandstone. ChemCam observations at the Dillinger outcrop on Sols 606-630 found thin layers of high $\mathrm{Mn}$ on three erosion-resistant fin-like features, which appear throughout the outcrop and are interpreted as post-depositional fracture fills. ${ }^{87}$ Precipitation of $\mathrm{Mn}$ minerals requires abundant water and strongly oxidizing conditions. On the Earth, concentrated Mn deposits did not occur until after the rise of oxygenic photosynthesis, which changed redox conditions across the planet. The reddish color of most free surfaces on Mars may suggest that the surface is highly oxidized. However, Mössbauer-spectra obtained on Mars by Spirit in Gusev crater showed a surprisingly low degree of oxidation as only about $40 \%$ of the iron of the soil was present in ferric phases. ${ }^{56}$ Even small airborne dust particles collected by on-board magnets turned out not to be fully oxidized..$^{\mathbf{8 8 - 9 0}}$ Nevertheless, the abundance of ferric phases on the surface of Mars demonstrates the occurrence of at least partially oxidizing conditions. ${ }^{91}$ However, until recently there was little evidence that conditions on Mars were ever oxidizing enough to produce Mn-rich minerals. Given the association between Mn-rich rocks and the redox state of surface environments on the Earth, observations of anomalous Mn enrichments on Mars raise important questions about past environmental conditions on the planet. Additionally, observations of Mn enrichments from the Opportunity rover on the other side of the planet suggest that the strongly oxidizing conditions present at Gale were not simply local in nature. Thin Mn-rich rock coatings were found underneath rocks in Endeavor crater. ${ }^{92}$ Overall, these observations of high Mn materials suggest that, at some point in the past, conditions on Mars were wet and more strongly oxidizing than they are today, and open up the possibility that the Martian atmosphere contained considerably more free oxygen. ${ }^{87}$

\section{Zinc detection and implications}

More than $10 \mathrm{Zn}$-enriched points have been detected at the Kimberley formation (Sols $>600$ ) with high $\mathrm{ZnO}$ content ranging from $1.0 \mathrm{wt} \%$ to a maximum of $7.5 \mathrm{wt} \%$ (Yarrada, Sol 628). Almost all of those $\mathrm{Zn}$-enriched targets are localized at the Dillinger member of the Kimberley formation, where high Mn and alkali contents were also detected,,$^{73,87}$ but probably in different phases. The Dillinger member consists of medium- to fine-grained sandstones with low angle cross-bedding representing a complex southwesterly mixed fluvial-aeolian system deposition..$^{93}$ Furthermore, the Dillinger member is also crosscut by fractures containing a resistant material that indicate a later stage water circulation within the member. Chemistry at the Kimberley outcrop is proving to be anomalous in a number of respects. As mentioned previously, the region is especially enriched in potassium, ${ }^{73}$ reflecting the substantial fraction of K-feldspar ( $20 \mathrm{wt} \%$ ) detected by the CheMin instrument. ${ }^{94}$ Relatively abundant fluorine detections were made, ${ }^{37}$ and the apparent fracture-filling material was found to contain high concentrations (>10 wt\%) of manganese-oxide minerals. ${ }^{87}$ $\mathrm{Zn}$ enrichment turns out to be independent of the textures of the rocks detected in that stratigraphic member, from fine- and coarse-grained sandstones to pebbly conglomerates and resistant fins. It is detected uniformly at all depths within the rocks by ChemCam and high detections were made by APXS in the same area, confirming the local enrichment. ${ }^{95}$ The lack of sulfur enhancement or other chalcophile elements in the ChemCam, APXS or CheMin analyses suggests that $\mathrm{Zn}$ is not present in the common terrestrial or sphalerite ( $\mathrm{ZnS}$ ) phase. Alternatively, $\mathrm{Zn}$ could be in an amorphous clay phase, a cement or deposited as an oxide after hydrothermal alteration. ${ }^{42}$ Finally, $\mathrm{Zn}$ enrichments have been observed within lunar soils as vapor condensates from impact ejecta plumes. ${ }^{96}$

\section{$\mathrm{Mg}$ enrichments and raised ridges}

So-called "raised ridges" consist of narrow $(<1$ to $6 \mathrm{~mm}$ in total width; several $\mathrm{cm}$ in length), curvilinear ridges that are more resistant to erosion than the surrounding mudstone rock, creating a raised relief of several millimeters ${ }^{97,98}$ that have been intensively studied by ChemCam at YKB (Sheepbed member). ${ }^{75,79,99}$ Between Sols 125 and 288, over 6000 laser shots were targeted at 102 locations across ten different raised ridges. The bulk average composition of the raised ridges was found to be enriched in $\mathrm{MgO}$ by $1.2-1.7 \times$ over that of the surrounding mudstone and showing some of the highest $\mathrm{MgO}$ values measured to date (single shot maximum of $19.0 \mathrm{wt} \%$ ). ${ }^{79} \mathrm{Al}_{2} \mathrm{O}_{3}$ was found to be anti-correlated with $\mathrm{MgO}$, while $\mathrm{Li}$ is somewhat enriched where $\mathrm{MgO}$ is highest. ${ }^{75}$ Some ridges show a variation in composition with different layers on a sub-mm scale as shown by 600-shot depth profiles, where ChemCam probes more than one distinct layer. Overall, the average composition of the raised ridges is close to that of a $\mathrm{Mg}$ - and Fe-rich smectite, or saponite, ${ }^{79}$ which may also be the main clay mineral constituent of the host 
mudstone,$^{76}$ formed through diagenetic reaction of a dilute brine with, predominantly, olivine and amorphous material.99 These detailed analyses by ChemCam provide evidence of diagenesis and aqueous activity in the early post-depositional history of the YKB formation, consistent with a low salinity to brackish fluid at near-neutral or slightly alkaline $\mathrm{pH}$.

\section{Conclusions}

After more than 800 Sols on the surface of Mars and more than 180000 laser shots, we highlight the different lessons learned from the first use of LIBS in space. For data processing and element detection, new tools had to be developed to account for the specificity and uniqueness of Mars data. First, we noticed the presence of solar absorption lines in LIBS spectra that were underestimated prior to launch. As a result, the processing of $\mathrm{H}$ signals is more complex. More generally, background removal is a challenge with LIBS on geologic targets because the target albedo is slightly modified after each laser shot. A novel framework for fully customized baseline removal has now been developed $^{\mathbf{1 0 0}}$ and is being applied to ChemCam data with promising results. ${ }^{101}$ In theory, there should be a dark spectrum for each LIBS spectrum (i.e., each laser shot); in practice we have acquired a dark spectrum before or after each laser burst. Continua are subtracted; however at this point, it is not clear if there is any useful and original information in the LIBS continua. For wavelength calibration of LIBS spectra, a Ti target proved to be very helpful because of the large number of spectral lines. Higher order distance correction is still under development, but it is already known that bias with distance is relatively limited over the $2-5 \mathrm{~m}$ range where $95 \%$ of the data are acquired. As a whole, data processing of LIBS spectra from Mars is not so complex, but some limitations arise due to the lack of control of the different parameters of the experiment. Overall Martian spectra are of very high quality, with signal intensities slightly better than those obtained with instrument surrogates on the Earth, compared to laboratory tests in a similar environment.

Regarding chemistry, some elements that can be detected in the laboratory have not been seen on Mars yet (e.g., Pb, Cu). For other elements, more work is needed to refine their quantification. For instance, contribution of atmospheric $\mathrm{C}$ still needs to be calculated to distinguish low levels of carbon. ${ }^{31}$ By and large, the keys to success for quantitative analysis are the databases for multivariate and univariate techniques. The ChemCam team is still augmenting its reference dataset, to mimic the expected mineralogy and chemistry on Mars. ${ }^{23}$

With regard to the use of ChemCam, we find that remote (i.e. 2.3-6 $\mathrm{m}$ distance) sensing is indeed a clear advantage of LIBS for planetary exploration. However, targets are not uniformly distributed with distance as expected, but have been selected mostly within $3.5 \mathrm{~m}$ distance from the rover. We interpret this bias as being due primarily to the limited image resolutions that are available for pointing during tactical operations when only Navcam images are available. As a whole, the success of remote

Table 2 LIBS key characteristics on Mars, as benchmarked by ChemCam

-

\section{Origin of data}

Crater size

Reference

Rocks

Soils

$350-550 \mu \mathrm{m}$
$<509 \pm 32 \mu \mathrm{m}$
$1.1-1.4 \mathrm{~mm}$

Lab.

Mars

Both

\section{0 shots \\ 150 shots \\ $3 \times 3$ raster}

\section{Depth profile}

Ablation rate

Max. depth in rocks

Max. depth in soils

\section{Spectra}

\# shots affected by dust

\# shots for statistics

Burst RSD on rocks

\section{Activities}

Duty cycles

Laser shots average

Ave. activity
6-9 mm

10-15 mm

$\sim 20 \mathrm{~mm}$

$<10 \mu \mathrm{m}$ per pulse

$400 \mu \mathrm{m}$

$3.5 \mathrm{~mm}$

$\begin{array}{ll}1-5 & \text { Mars } \\ >20 & \text { Mars } \\ 4-8 \% & \text { Mars }\end{array}$

Mars

Mars

Mars

Lab.

Lab.

Lab.

Mars

Mars

Mars

Mars

Mars

Mars

Mars

Mars
Comments

See Maurice et $a l^{2}$ on Al plate

Stephen target $2.3 \mathrm{~m}$ distance 30 shots

This study and Wiens et al. ${ }^{3}$

Depend on surface roughness and amount of dust

This study and Wiens et $a l^{3}$

From soft dolomite and pressed simulant

From $40-80 \mu \mathrm{m}$ sieved simulant

See Lasue et $a .^{32}$ for details

After $\sim 20$ dust free shots. Total emission 
science is mainly due to the high-performance pointing capability of the Remote Sensing Mast that carries ChemCam.

ChemCam is a very versatile instrument because many parameters can be adjusted. However, to avoid the potential for increased matrix effects, the laser energy should not be adjusted. The laser repetition rate has no influence. The number of laser shots per burst should be optimally greater than 25 shots: 5 to remove dust or surface contamination, 20 to minimize shot noise. Very generally, there is a large flexibility in terms of the geometrical arrangement of observation points in the form of rasters. Many combinations were tried, but $3 \times 3,1 \times 5$, and $1 \times$ 10 were the ones most often used. LIBS is also a very rapid technique. Considering different overheads, ChemCam's typical durations of a few minutes per raster are far faster and more energy efficient than the days it can take to position the rover and arm to provide alternative in situ measurements.

Several original results were obtained as part of this review (Table 2). First about pit sizes, laboratory data as well as Mars measurements show that LIBS craters on Mars are up to half a millimeter diameter in rocks, and 2-3 times larger in soils. We have quantified dust removal by the laser shock wave: a circular dust-free area of $\sim 1 \mathrm{~cm}$ diameter arises from 30 shots, and nearly $2 \mathrm{~cm}$ from 150 shots. Rasters can clear several $\mathrm{cm}^{2}$. We also looked at crater depths. More shots excavate deeper, but saturation is rapidly reached. Most laboratory data do not excavate more than half a millimeter in solid samples. In soils, the crater is much larger, with depths up to a few millimeters. Almost no surface coatings have been observed with ChemCam. As a whole, we conclude that advantages for LIBS that were discussed prior to the ChemCam launch are confirmed; those capabilities are now quantified.

Experience on the MSL mission has shown that this ability to quickly survey the geochemistry of several targets in a vicinity is of great value for its own sake, but also in aiding rapid understanding of an environment for efficient use of mission time. Moreover, it provides valuable support to decisions about selecting where and whether to make observations with more time- and resource-intensive tools in the rover's instrument suite. This value as a tactical tool will soon be further enhanced by the implementation of an autonomous target-selection capability. The Autonomous Exploration for Gathering Increased Science (AEGIS) system, a software package operational since 2010 on the MER Opportunity rover, ${ }^{102}$ has been adapted for ChemCam and is expected to be available operationally in late 2015. ${ }^{103}$ AEGIS will allow the Curiosity rover to autonomously select targets and acquire ChemCam observations of them, during mission phases when the science team on the Earth cannot review targeting images without incurring a mission delay. AEGIS will also enable autonomous, real-time refinement of ChemCam pointing for fine-scale targets, relieving the difficulty of targeting such features. These capabilities will allow more rapid delivery of geochemical data, and faster progress for the mission when making decisions based on it.

Several key results highlight the potential of LIBS for geochemistry on Mars. For completeness, we assess here briefly the performance of ChemCam's non-LIBS capabilities, which have also been validated during Season-1: passive spectroscopy and micro-imaging. The RMI has proven to be decisive for the interpretation of LIBS data. The resolution (the angular pixel size $\sim 20 \mu \mathrm{rad}$ per pixel corresponds to $\sim 40 \mu \mathrm{m}$ at $2 \mathrm{~m}$ ) is ideal to localize the LIBS pits, to understand the geological context, the amount of dust covering the targets, and to identify veins, mineral grains, etc. Accurate registration of RMI images in Navcam, Mastcam, and MAHLI images is important to data interpretation. The monochromatic output of the imager is not a major penalty for most of RMI objectives, e.g., to make a definitive distinction between bright dust and bright clasts. When necessary, a Mastcam color image (at $\sim 1 / 3$ of RMI's resolution) can be merged with an RMI image to create a single high-resolution color image. Passive spectroscopy is obtained without turning on the laser. Its field-of-view is $0.67 \mathrm{mrad}$. It covers the same spectral range as LIBS spectra, with the same spectral resolution but lower signal-to-noise because of the weakness of the input signal. This is especially true in the UV range due to the very low UV reflectance of most geological materials. The spectral range of ChemCam is designed for LIBS, and does provide coverage of IR wavelengths above $1 \mu \mathrm{m}$, which would benefit passive observations. Still, very interesting results were obtained from passive spectroscopy, ${ }^{104}$ especially at distances beyond the LIBS range. The spectral resolution is more than enough for passive spectroscopy of Mars rocks, and very advantageous for sky observations. ${ }^{105}$

The next opportunity to use LIBS in space will once again be on Mars. SuperCam is a suite of four co-boresighted instruments (LIBS, Raman spectroscopy, visible/near-IR spectroscopy, and color micro-imaging) that is scheduled to fly on board the NASA Mars2020 rover. ${ }^{106,107}$ The LIBS, visible spectroscopy, and imaging capabilities rely heavily on ChemCam heritage, while the remote Raman and IR spectroscopies will be new tools on the surface of Mars. Together, these techniques will characterize at sub-millimeter scales the mineralogy and elemental chemistry of the Martian surface, and will join the search for extant organic materials. These techniques are fundamental investigations that lay the groundwork for all types of Mars geochemistry and astrobiology investigations. Each technique has its range of target distance capabilities, from $2 \mathrm{~m}$ to $7 \mathrm{~m}$ for LIBS, up to $12 \mathrm{~m}$ for Raman, up to the horizon for visible/IR and RMI. Up to $7 \mathrm{~m}$, the capability of LIBS to remove dust will be important to extract unambiguous mineral signatures with Raman and IR spectroscopy. SuperCam will clearly benefit in many ways from our experience using ChemCam.

\section{Acknowledgements}

This work was supported in France by the French Space Agency (CNES), the Centre National de la Recherche Scientifique (CNRS), and many institutes and universities across the country. Collaboration with colleagues in the US was funded by NASA's Mars Program Office.

\section{References}

1 R. C. Wiens, S. Maurice and The ChemCam Team, ChemCam: Chemostratigraphy by the First Mars Microprobe, 
Elements, February 2015, vol. 11, pp. 33-38, DOI: 10.2113/ gselements.11.1.33.

2 S. Maurice, R. C. Wiens, M. Saccoccio, B. Barraclough, O. Gasnault, O. Forni, N. Mangold, D. Baratoux, S. Bender, G. Berger, J. Bernardin, M. Berthé, N. Bridges, D. Blaney, M. Bouyé, P. Caïs, B. Clark, S. Clegg, A. Cousin, D. Cremers, A. Cros, L. DeFlores, C. Derycke, B. Dingler, G. Dromart, B. Dubois, M. Dupieux, E. Durand, L. d'Uston, C. Fabre, B. Faure, A. Gaboriaud, T. Gharsa, K. Herkenhoff, E. Kan, L. Kirkland, D. Kouach, J.-L. Lacour, Y. Langevin, J. Lasue, S. Le Mouélic, M. Lescure, E. Lewin, D. Limonadi, G. Manhès, P. Mauchien, C. McKay, P.-Y. Meslin, Y. Michel, E. Miller, H. E. Newsom, G. Orttner, A. Paillet, L. Parès, Y. Parot, R. Pérez, P. Pinet, F. Poitrasson, B. Quertier, B. Sallé, C. Sotin, V. Sautter, H. Séran, J. J. Simmonds, J.-B. Sirven, R. Stiglich, N. Striebig, J.-J. Thocaven, M. J. Toplis and D. Vaniman, The ChemCam Instrument Suite on the Mars Science Laboratory (MSL) Rover: Science Objectives and Mast Unit Description, Space Sci. Rev., 2012, 170(1-4), 95166, DOI: 10.1007/s11214-012-9912-2.

3 R. C. Wiens, S. Maurice, B. Barraclough, M. Saccoccio, W. C. Barkley, J. F. Bell, S. Bender, J. Bernardin, D. Blaney, J. Blank, M. Bouyé, N. Bridges, N. Bultman, P. Caïs, R. C. Clanton, B. Clark, S. Clegg, A. Cousin, D. Cremers, A. Cros, L. DeFlores, D. Delapp, R. Dingler, C. d'Uston, M. Darby Dyar, T. Elliott, D. Enemark, C. Fabre, M. Flores, O. Forni, O. Gasnault, T. Hale, C. Hays, K. Herkenhoff, E. Kan, L. Kirkland, D. Kouach, D. Landis, Y. Langevin, N. Lanza, F. LaRocca, J. Lasue, J. Latino, D. Limonadi, C. Lindensmith, C. Little, N. Mangold, G. Manhes, P. Mauchien, C. McKay, E. Miller, J. Mooney, R. V. Morris, L. Morrison, T. Nelson, H. Newsom, A. Ollila, M. Ott, L. Pares, R. Perez, F. Poitrasson, C. Provost, J. W. Reiter, T. Roberts, F. Romero, V. Sautter, S. Salazar, J. J. Simmonds, R. Stiglich, S. Storms, N. Striebig, J.-J. Thocaven, T. Trujillo, M. Ulibarri, D. Vaniman, N. Warner, R. Waterbury, R. Whitaker, J. Witt and B. Wong-Swanson, The ChemCam Instrument Suite on the Mars Science Laboratory (MSL) Rover: Body Unit and Combined System Tests, Space Sci. Rev., 2012, 170(1-4), 167-227, DOI: 10.1007/s11214-012-9902-4.

4 R. C. Wiens, S. Maurice, J. Lasue, O. Forni, R. B. Anderson, S. Clegg, S. Bender, D. Blaney, B. L. Barraclough, A. Cousin, L. Deflores, D. Delapp, M. D. Dyar, C. Fabre, O. Gasnault, N. Lanza, J. Mazoyer, N. Melikechi, P.-Y. Meslin, H. Newsom, A. Ollila, R. Perez, R. L. Tokar and D. Vaniman, Pre-flight calibration and initial data processing for the ChemCam laser-induced breakdown spectroscopy instrument on the Mars Science Laboratory rover, Spectrochim. Acta, Part B, 2013, 82, 1-27, DOI: 10.1016/j.sab.2013.02.003.

5 S. Le Mouélic, O. Gasnault, K. E. Herkenhoff, N. T. Bridges, Y. Langevin, N. Mangold, S. Maurice, R. C. Wiens, P. Pinet, H. E. Newsom, R. G. Deen, J. F. Bell, J. R. Johnson, W. Rapin, B. Barraclough, D. L. Blaney, L. Deflores, J. Maki,
M. C. Malin, R. Pérez and M. Saccoccio, The ChemCam Remote Micro-Imager at Gale crater: review of the first year of operations on Mars, Icarus, 2015, 249, 93-107, DOI: 10.1016/j.icarus.2014.05.030.

6 C. Yana, C. Donny, P. Guillemot, V. Lafaille, E. Lorigny, L. Peret, A. Nelson, R. Wiens, B. Barraclough, O. Gasnault and S. Maurice, Two years of operations of the ChemCam instrument on-board the Curiosity rover at FIMOC, the French operations center for Mars instruments, Thirteenth International Conference on Space Operations, May 2014, DOI: 10.2514/6.2014-1901.

$7 \mathrm{H}$. Newsom, Planetary science: clays in the history of Mars, Nature, 2005, 438(7068), 570-571, DOI: 10.1038/438570a.

8 F. Poulet, J.-P. Bibring, J. F. Mustard, A. Gendrin, N. Mangold, Y. Langevin, R. E. Arvidson, B. Gondet and C. Gomez, Phyllosilicates on Mars and implications for early Martian climate, Nature, 2005, 438(7068), 623-627, DOI: 10.1038/nature04274.

9 J.-P. Bibring, Y. Langevin, J. F. Mustard, F. Poulet, R. Arvidson, A. Gendrin, B. Gondet, N. Mangold, P. Pinet, F. Forget, et al., Global Mineralogical and Aqueous Mars History Derived from OMEGA/Mars Express Data, Science, 2006, 312(5772), 400-404, DOI: 10.1126/science.1122659.

10 F.-T. Chau, Y.-Z. Liang, J. Gao and X.-G. Shao, Chemometrics: From Basics to Wavelet Transform (Chemical Analysis: A Series of Monographs on Analytical Chemistry and Its Applications), Interscience Publishers, Incorporated, March 2004, ISBN: 978-0-471-20242-4; P. R. Christensen, R. V. Morris, M. D. Lane, J. L. Bandfield and M. C. Malin, Global mapping of Martian hematite mineral deposits: remnants of water-driven processes on early Mars, J. Geophys. Res., 2001, 106(E10), 23873-23886, DOI: 10.1029/2000JE001415.

11 N. Melikechi, A. Mezzacappa, A. Cousin, N. L. Lanza, J. Lasue, S. M. Clegg, G. Berger, R. C. Wiens, S. Maurice, R. L. Tokar, S. Bender, O. Forni, E. A. Breves, M. D. Dyar, J. Frydenvang, D. Delapp, O. Gasnault, H. Newsom, A. M. Ollila, E. Lewin, B. C. Clark, B. L. Ehlmann, D. Blaney and C. Fabre, Correcting for variable lasertarget distances of laser-induced breakdown spectroscopy measurements with ChemCam using emission lines of Martian dust spectra, Spectrochim. Acta, Part B, 2014, 96, 51-60, DOI: 10.1016/j.sab.2014.04.004.

12 A. Cousin, O. Forni, S. Maurice, O. Gasnault, C. Fabre, V. Sautter, R. C. Wiens and J. Mazoyer, Laser induced breakdown spectroscopy library for the Martian environment, Spectrochim. Acta, Part B, 2011, 66(11-12), 805-814, DOI: 10.1016/j.sab.2011.10.004.

13 R. E. Russo, A. A. Bol'shakov, X. Mao, C. P. McKay, D. L. Perry and O. Sorkhabi, Laser Ablation Molecular Isotopic Spectrometry, Spectrochim. Acta, Part B, 2011, 66(2), 99-104, DOI: 10.1016/j.sab.2011.01.007.

14 M. Gaft, L. Nagli, N. Eliezer, Y. Groisman and O. Forni, Elemental analysis of halogens using molecular emission by laser-induced breakdown spectroscopy in air, Spectrochim. Acta, Part B, 2014, 98, 39-47, DOI: 10.1016/ j.sab.2014.05.011. 
15 C. G. Parigger, Atomic and molecular emissions in laserinduced breakdown spectroscopy, Spectrochim. Acta, Part $B, 2013$, 79-80, 4-16, DOI: 10.1016/j.sab.2012.11.012.

16 C. Fabre, A. Cousin, R. C. Wiens, A. Ollila, O. Gasnault, S. Maurice, V. Sautter, O. Forni, J. Lasue, R. Tokar, D. Vaniman and N. Melikechi, In situ calibration using univariate analyses based on the on-board ChemCam targets: first prediction of Martian rock and soil compositions, Spectrochim. Acta, Part B, 2014, 99, 34-51, DOI: 10.1016/j.sab.2014.03.014.

17 A. M. Ollila, H. E. Newsom, B. Clark, R. C. Wiens, A. Cousin, J. G. Blank, N. Mangold, V. Sautter, S. Maurice, S. M. Clegg, O. Gasnault, O. Forni, R. Tokar, E. Lewin, M. D. Dyar, J. Lasue, R. Anderson, S. M. McLennan, J. Bridges, D. Vaniman, N. Lanza, C. Fabre, N. Melikechi, G. M. Perrett, J. L. Campbell, P. L. King, B. Barraclough, D. Delapp, S. Johnstone, P.-Y. Meslin, A. Rosen-Gooding and J. Williams, Trace element geochemistry (Li, Ba, Sr, and $\mathrm{Rb}$ ) using Curiosity's ChemCam: early results for Gale crater from Bradbury landing site to Rocknest, J. Geophys. Res.: Planets, 2014, 119(1), 255-285, DOI: 10.1002/ 2013JE004517.

18 M. Clegg Samuel, S. Elizabeth, M. Darby Dyar, J. E. Barefield and R. C. Wiens, Multivariate analysis of remote laserinduced breakdown spectroscopy spectra using partial least squares, principal component analysis, and related techniques, Spectrochim. Acta, Part B, 2009, 64(1), 79-88, DOI: $10.1016 /$ j.sab.2008.10.045.

19 J. Lasue, R. C. Wiens, T. F. Stepinski, O. Forni, S. M. Clegg, S. Maurice and ChemCam team, Nonlinear mapping technique for data visualization and clustering assessment of LIBS data: application to ChemCam data, Anal. Bioanal. Chem., 2011, 400(10), 3247-3260, DOI: 10.1007/s00216-011-4747-3.

20 M. D. Dyar, M. L. Carmosino, E. A. Speicher, M. V. Ozanne, S. M. Clegg and R. C. Wiens, Comparison of partial least squares and lasso regression techniques for laser-induced breakdown spectroscopy of geological samples, Spectrochim. Acta, Part B, 2012, 70, 51-67, DOI: 10.1016/ j.sab.2012.04.011.

21 M. Ollila Ann, J. Lasue, H. E. Newsom, R. A. Multari, R. C. Wiens and S. M. Clegg, Comparison of two partial least squares-discriminant analysis algorithms for identifying geological samples with the ChemCam laserinduced breakdown spectroscopy instrument, Appl. Opt., 2012, 51(7), B130-B142, DOI: 10.1364/AO.51.00B130.

22 O. Forni, S. Maurice, O. Gasnault, R. C. Wiens, A. Cousin, S. M. Clegg, J.-B. Sirven and J. Lasue, Independent component analysis classification of laser induced breakdown spectroscopy spectra, Spectrochim. Acta, Part B, 2013, 86, 31-41, DOI: 10.1016/j.sab.2013.05.003.

23 R. B. Anderson, S. M. Clegg, B. L. Ehlmann, R. V. Morris, S. M. McLennan, T. Boucher, M. D. Dyar, R. McInroy, D. Delapp, R. C. Wiens, J. Frydenvang, O. Forni, S. Maurice, O. Gasnault, J. Lasue and C. Fabre, Expanded Compositional Database for ChemCam Quantitative Calibration, 8th International Conference on Mars,
Pasadena, California, 14-18 July 2014, LPI Contribution No. 1791, p. 1275.

24 C. Fabre, S. Maurice, A. Cousin, R. C. Wiens, O. Forni, V. Sautter and D. Guillaume, Onboard calibration igneous targets for the Mars Science Laboratory Curiosity rover and the Chemistry Camera laser induced breakdown spectroscopy instrument, Spectrochim. Acta, Part B, 2011, 66, 280-289, DOI: 10.1016/j.sab.2011.03.012.

25 D. Vaniman, M. D. Dyar, R. Wiens, A. Ollila, N. Lanza, J. Lasue, J. M. Rhodes, S. Clegg and H. Newsom, Ceramic ChemCam calibration targets on Mars Science Laboratory, Space Sci. Rev., 2012, 170(1-4), 229-255, DOI: 10.1007/ s11214-012-9886-0.

26 A. Cremers David and L. J. Radziemski, Detection of chlorine and fluorine in air by laser-induced breakdown spectrometry, Anal. Chem., 1983, 55(8), 1252-1256, DOI: 10.1021/ac00259a017.

27 M. Nachon, N. Mangold, A. Cousin, R. B. Anderson, J. G. Blank, F. Calef, S. Clegg, C. Fabre, M. Fisk, O. Gasnault, L. C. Kah, R. Kronyak, J. Lasuer, P.-Y. Meslin, S. Le Mouélic, S. Maurice, D. Z. Oehler, V. Payre, W. Rapin, D. Sumner, K. Stack, S. Schröder and R. C. Wiens, Diagenetic Features Analyzed by ChemCam/ Curiosity at Pahrump Hills, Gale crater, Mars, 46th Lunar and Planetary Science Conference, held March 16-20, 2015 in The Woodlands, Texas, LPI Contribution No. 1832, March 2015, p. 1524.

28 D. L. Blaney, R. C. Wiens, S. Maurice, S. M. Clegg, R. B. Anderson, L. C. Kah, S. Le Mouélic, A. Ollila, N. Bridges, R. Tokar, G. Berger, J. C. Bridges, A. Cousin, B. Clark, M. D. Dyar, P. L. King, N. Lanza, N. Mangold, P.-Y. Meslin, H. Newsom, S. Schröder, S. Rowland, J. Johnson, L. Edgar, O. Gasnault, O. Forni, M. Schmidt, W. Goetz, K. Stack, D. Sumner, M. Fisk and M. B. Madsen, Chemistry and texture of the rocks at Rocknest, Gale crater: evidence for sedimentary origin and diagenetic alteration, J. Geophys. Res.: Planets, 2014, 119(9), 2109-2131, DOI: 10.1002/2013JE004590.

29 S. Schröder, P.-Y. Meslin, O. Gasnault, S. Maurice, A. Cousin, R. C. Wiens, W. Rapin, M. D. Dyar, N. Mangold, O. Forni, M. Nachon, S. Clegg, J. R. Johnson, J. Lasue, S. Le Mouélic, A. Ollila, P. Pinet, V. Sautter and D. Vaniman, Hydrogen detection with ChemCam at Gale crater, Icarus, 2015, 249, 43-61, DOI: 10.1016/ j.icarus.2014.08.029.

30 P.-Y. Meslin, O. Gasnault, O. Forni, S. Schröder, A. Cousin, G. Berger, S. M. Clegg, J. Lasue, S. Maurice and V. Sautter, et. al., Soil Diversity and Hydration as Observed by ChemCam at Gale crater, Mars, Science, 2013, 341(6153), DOI: $10.1126 /$ science.1238670.

31 A. M. Ollila, J. G. Blank, R. C. Wiens, J. Lasue, H. E. Newsom, S. M. Clegg, A. Cousin and S. Maurice, Preliminary Results on the Capabilities of the ChemCam Laser-Induced Breakdown Spectroscopy (LIBS) Instrument to Detect Carbon on Mars, 42nd Lunar and Planetary Science Conference, held March 7-11, 2011 at The 
Woodlands, Texas, LPI Contribution No. 1608, March 2011, p. 2395.

32 J. Lasue, S. Maurice, A. Cousin, O. Forni, P.-Y. Meslin, W. Rapin, S. Schröder, A. Ollila, G. Berger, N. Bridges, S. M. Clegg, C. d'Uston, C. Fabre, O. Gasnault, W. Goetz, J. Johnson, N. Lanza, S. Le Mouélic, M. B. Madsen, N. Mangold, N. Melikechi, A. Mezzacappa, H. Newsom and R. C. Wiens, ChemCam Analysis of Martian Fine Dust, 45th Lunar and Planetary Science Conference, held 17-21 March, 2014 at The Woodlands, Texas, MSL Science Team, LPI Contribution No. 1777, March 2014, p. 1224.

33 J. G. Blank, A. M. Ollila, N. L. Lanza, O. Forni, N. Mangold, M. Nachon, S. M. Clegg, A. Yen, S. Maurice and R. C. Wiens, Detection of phosphorous by ChemCam in Gale crater, 46th Lunar and Planetary Science Conference, held March 16-20, 2015 in The Woodlands, Texas, LPI Contribution No. 1832, 2015, p. 2850.

34 B. Sallé, J.-L. Lacour, E. Vors, P. Fichet, S. Maurice, D. A. Cremers and R. C. Wiens, Laser-Induced Breakdown Spectroscopy for Mars surface analysis: capabilities at stand-off distances and detection of chlorine and sulfur elements, Spectrochim. Acta, Part B, 2004, 59(9), 14131422, DOI: 10.1016/j.sab.2004.06.006.

35 M. D. Dyar, M. T. Jonathan, H. Seth, M. C. Samuel, C. W. Roger and D. L. Melissa, Strategies for Mars remote Laser-Induced Breakdown Spectroscopy analysis of sulfur in geological samples, Spectrochim. Acta, Part B, 2011, 66(1), 39-56, DOI: 10.1016/j.sab.2010.11.016.

36 D. A. Cremers and J. R. Leon, Handbook of laser-induced breakdown spectroscopy, Cambridge University, 2006, vol. 25.

37 O. Forni, M. Gaft, M. J. Toplis, S. M. Clegg, S. Maurice, R. C. Wiens, icolas Mangold, O. Gasnault, V. Sautter, S. Le Mouélic, P.-Y. Meslin, M. Nachon, R. E. McInroy, A. M. Ollila, A. Cousin, J. C. Bridges, N. L. Lanza and M. D. Dyar, First detection of fluorine on Mars: Implications for Gale crater's geochemistry, Geophys. Res. Lett., 2015, 42(4), 1020-1028, DOI: 10.1002/2014GL062742.

38 C. Fabre, M.-C. Boiron, J. Dubessy, A. Chabiron and B. Charoy, Martin Crespo, Tomas, Advances in lithium analysis in solids by means of laser-induced breakdown spectroscopy: an exploratory study, Geochim. Cosmochim. Acta, 2002, 66(8), 1401-1407, DOI: 10.1016/S0016-7037(01) 00858-4.

39 V. Sautter, C. Fabre, O. Forni, M. J. Toplis, A. Cousin, A. M. Ollila, P.-Y. Meslin, S. Maurice, R. C. Wiens, D. Baratoux, N. Mangold, S. Le Mouélic, O. Gasnault, G. Berger, J. Lasue, R. A. Anderson, E. Lewin, M. Schmidt, D. Dyar, B. L. Ehlmann, J. Bridges, B. Clark and P. Pinet, Igneous mineralogy at Bradbury Rise: the first ChemCam campaign at Gale crater, J. Geophys. Res.: Planets, 2014, 119(1), 30-46, DOI: 10.1002/2013JE004472.

40 V. Sautter, M. J. Toplis, R. C. Wiens, A. Cousin, C. Fabre, O. Gasnault, S. Maurice, O. Forni, J. Lasue, A. Ollila, J. C. Bridges, N. Mangold, S. Le Mouélic, M. Fisk, P.-Y. Meslin, P. Beck, P. Pinet, L. Le Deit, W. Rapin, E. M. Stolper, H. Newsom, D. Dyar, N. Lanza, D. Vaniman,
S. Clegg and J. J. Wray, In situ evidence for continental crust on early Mars, Nat. Geosci., 2015, 8(8), 605-609, DOI: 10.1038/ngeo2474.

41 N. L. Lanza, W. W. Fischer, R. C. Wiens, J. Grotzinger, A. M. Ollila, A. Cousin, R. B. Anderson, B. C. Clark, R. Gellert, N. Mangold, S. Maurice, S. Le Mouélic, M. Nachon, M. Schmidt, J. Berger, S. M. Clegg, O. Forni, C. Hardgrove, N. Melikechi, H. E. Newsom and V. Sautter, High manganese concentrations in rocks at Gale crater, Mars, Geophys. Res. Lett., 2014, 41(16), 5755-5763, DOI: 10.1002/2014GL060329.

42 J. Lasue, S. M. Clegg, O. Forni, A. Cousin, R. C. Wiens, N. Lanza, N. Mangold, O. Gasnault and S. Maurice, MSL Science Team, Detection of $\mathrm{Zn}$ with ChemCam on Mars, 46th Lunar and Planetary Science Conference, held March 16-20, 2015 in The Woodlands, Texas, LPI Contribution No. 1832, March 2015, p. 1413.

43 A. K. Knight, N. L. Scherbarth, D. A. Cremers and M. J. Ferris, Characterization of laser-induced breakdown spectroscopy (LIBS) for application to space exploration, Appl. Spectrosc., 2000, 54(3), 331-340, DOI: 10.1366/ 0003702001949591.

44 M. C. McCanta, P. A. Dobosh, M. D. Dyar and H. E. Newsom, Testing the veracity of LIBS analyses on Mars using the LIBSSIM program, Planet. Space Sci., 2013, 81, 48-54, DOI: 10.1016/j.pss.2013.03.004.

45 D. Cremers and R. Chinni, Laser-Induced Breakdown Spectroscopy-Capabilities and Limitations, Appl. Spectrosc. Rev., 2009, 44(6), 457-506, DOI: 10.1080/ 05704920903058755.

46 N. J. McMillan, S. Rees, K. Kochelek and C. McManus, Geological Applications of Laser-Induced Breakdown Spectroscopy, Geostand. Geoanal. Res., 2014, 38, 329-343, DOI: 10.1111/j.1751-908X.2014.00308.x.

47 A. Cousin, V. Sautter, N. Mangold, C. Fabre, O. Forni, W. Rapin, M. Fisk, O. Gasnault, N. Lanza, J. Lasue, P.-Y. Meslin, H. Newsom, A. Ollila, V. Payre, R. C. Wiens and S. Maurice, Igneous Rock Classification at Gale (Sols 13-800), 46th Lunar and Planetary Science Conference, held March 16-20, 2015 in The Woodlands, Texas, LPI Contribution No. 1832, March 2015, p. 2452.

48 B. Sallé, D. A. Cremers, S. Maurice and R. C. Wiens, Laserinduced breakdown spectroscopy for space exploration applications: influence of the ambient pressure on the calibration curves prepared from soil and clay samples, Spectrochim. Acta, Part B, 2005, 60(4), 479-490, DOI: 10.1016/j.sab.2005.02.009.

49 E. M. Stolper, M. B. Baker, M. E. Newcombe, M. E. Schmidt, A. H. Treiman, A. Cousin, M. D. Dyar, M. R. Fisk, R. Gellert, P. L. King, et al. The Petrochemistry of Jake_M: A Martian Mugearite, Science, 2013, 341(6153), DOI: 10.1126/ science.1239463.

50 M. E. Schmidt, J. L. Campbell, R. Gellert, G. M. Perrett, A. H. Treiman, D. L. Blaney, A. Ollila, F. J. Calef, L. Edgar, B. E. Elliott, J. Grotzinger, J. Hurowitz, P. L. King, M. E. Minitti, V. Sautter, K. Stack, J. A. Berger, J. C. Bridges, B. L. Ehlmann, O. Forni, L. A. Leshin, 
K. W. Lewis, S. M. McLennan, D. W. Ming, H. Newsom, I. Pradler, S. W. Squyres, E. M. Stolper, L. Thompson, S. VanBommel and R. C. Wiens, Geochemical diversity in first rocks examined by the Curiosity Rover in Gale crater: evidence for and significance of an alkali and volatile-rich igneous source, J. Geophys. Res.: Planets, 2014, 119(1), 6481, DOI: 10.1002/2013JE004481.

51 A. Cousin, P.-Y. Meslin, R. C. Wiens, W. Rapin, N. Mangold, C. Fabre, O. Gasnault, O. Forni, R. Tokar, A. Ollila, S. Schröder, J. Lasue, S. Maurice, V. Sautter, H. Newsom, D. Vaniman, S. Le Mouélic, D. Dyar, G. Berger, D. Blaney, M. Nachon, G. Dromart, N. Lanza, B. Clark, S. Clegg, W. Goetz, J. Berger, B. Barraclough and D. Delapp, Compositions of coarse and fine particles in Martian soils at Gale: a window into the production of soils, Icarus, 2015, 249, 22-42, DOI: 10.1016/j.icarus.2014.04.052.

52 M. Collinet, E. Médard, B. Charlier, A. Vander, G. Jacqueline and L. Timothy, Melting of the primitive Martian mantle at 0.5-2.2 GPa and the origin of basalts and alkaline rocks on Mars, Earth Planet. Sci. Lett., 2015, 427, 83-94, DOI: 10.1016/ j.epsl.2015.06.056.

53 S. W. Squyres, R. E. Arvidson, D. L. Blaney, B. C. Clark, L. Crumpler, W. H. Farrand, S. Gorevan, K. E. Herkenhoff, J. Hurowitz, A. Kusack, H. Y. McSween, D. W. Ming, R. V. Morris, S. W. Ruff, A. Wang and A. Yen, Rocks of the Columbia Hills, J. Geophys. Res., 2006, 111(E2), DOI: 10.1029/2005JE002562.

54 D. Baratoux, H. Samuel, C. Michaut, M. J. Toplis, M. Monnereau, M. Wieczorek, R. Garcia and K. Kurita, Petrological constraints on the density of the Martian crust, J. Geophys. Res.: Planets, 2014, 119(7), 1707-1727, DOI: 10.1002/2014JE004642.

55 S. W. Squyres, R. E. Arvidson, E. T. Baumgartner, J. F. Bell, P. R. Christensen, S. Gorevan, K. E. Herkenhoff, G. Klingelhöfer, M. B. Madsen, R. V. Morris, R. Rieder and R. A. Romero, Athena Mars rover science investigation, J. Geophys. Res., 2003, 108(E12), 3, DOI: 10.1029/2003JE002121.

56 G. Klingelhöfer, R. V. Morris, B. Bernhardt, C. Schröder, D. S. Rodionov, P. A. de Souza Jr, A. Yen, R. Gellert, E. N. Evlanov, B. Zubkov, J. Foh, U. Bonnes, E. Kankeleit, P. Gütlich, D. W. Ming, F. Renz, T. Wdiwiak, S. W. Squyres and R. E. Arvidson, Jarosite and hematite at Meridiani Planum from Opportunity's Mössbauer Spectrometer, Science, 2004, 306, 1740-1745.

57 S. R. Taylor and S. McLennan, Planetary Crusts: Their Composition, Origin and Evolution, Planetary Crusts: Their Composition, Origin and Evolution, Cambridge Catalogue, January 2009.

58 D. F. Blake, R. V. Morris, G. Kocurek, S. M. Morrison, R. T. Downs, D. Bish, D. W. Ming, K. S. Edgett, D. Rubin, W. Goetz, et al., Curiosity at Gale crater, Mars: Characterization and Analysis of the Rocknest Sand Shadow, Science, 2013, 341(6153), DOI: 10.1126/ science.1239505.

59 D. L. Bish, D. F. Blake, D. T. Vaniman, S. J. Chipera, R. V. Morris, D. W. Ming, A. H. Treiman, P. Sarrazin,
S. M. Morrison, R. T. Downs, et al., X-ray Diffraction Results from Mars Science Laboratory: Mineralogy of Rocknest at Gale crater, Science, 2013, 341(6153), DOI: 10.1126/science.1238932.

60 A. S. Yen, R. Gellert, C. Schröder, R. V. Morris, J. F. Bell, A. T. Knudson, B. C. Clark, D. W. Ming, J. A. Crisp, R. E. Arvidson, D. Blaney, J. Brückner, P. R. Christensen, D. J. Desmarais, P. A. de Souza, T. E. Economou, A. Ghosh, B. C. Hahn, K. E. Herkenhoff, L. A. Haskin, J. A. Hurowitz, B. L. Joliff, J. R. Johnson, G. Klingelhöfer, M. B. Madsen, S. M. McLennan, H. Y. McSween, L. Richter, R. Rieder, D. Rodionov, L. Soderblom, S. W. Squyres, N. J. Tosca, A. Wang, M. Wyatt and J. Zipfel, An integrated view of the chemistry and mineralogy of Martian soils, Nature, 2005, 436(7047), 4954, DOI: 10.1038/nature03637.

61 B. C. Clark, A. J. Castro, C. D. Rowe, A. K. Baird, P. H. Evans, H. J. Rose Jr, P. Toulmin III, K. Keil and W. C. Kelliher, Inorganic analyses of Martian surface samples at the Viking landing sites, Science, 1976, 194, 1283-1288, DOI: 10.1126/science.194.4271.1283.

62 H. E. Newsom, J. J. Hagerty and F. Goff, Mixed hydrothermal fluids and the origin of the Martian soil, $J$. Geophys. Res., 1999, 104(E4), 8717-8728, DOI: 10.1029/ 1998JE900043.

63 S. Maurice, W. Feldman, B. Diez, O. Gasnault, D. J. Lawrence, A. Pathare and T. Prettyman, Mars Odyssey neutron data: 1 . Data processing and models of water-equivalent-hydrogen distribution, J. Geophys. Res., 2011, 116(E11), DOI: 10.1029/2011JE003810.

64 F. J. Martín-Torres, M.-P. Zorzano, C. Armiens, I. Carrasco, A. Delgado-Bonal, M. Genzer, F. Gómez, J. Gómez-Elvira, R. Haberle, V. E. Hamilton, A.-M. Harri, H. Kahanpää, O. Kemppinen, M. T. Lemmon, A. Lepinette, J. Martín Soler, J. Martínez-Frías, M. Mischna, L. Mora, S. Navarro, C. Newman, M. A. de Pablo, J. Pla-García, V. Peinado, J. Polkko, S. C. R. Rafkin, M. Ramos, N. O. Rennó, M. Richardson, J. A. Rodríguez-Manfredi, J. J. Romeral Planelló, E. Sebastián, M. de la Torre Juárez, J. Torres, A. Ullán, R. Urquí, P. Valentín-Serrano, A. R. Vasavada and MSL Science Team, Highlights from the Rover Environmental Monitoring Station (REMS) on Board the Mars Science Laboratory: New Windows for Atmospheric Research on Mars, The Fifth International Workshop on the Mars Atmosphere: Modelling and Observation, held on January 13-16 2014, ed. F. Forget and M. Millour, Oxford, U.K., id. 1103, January 2014.

65 L. A. Leshin, P. R. Mahaffy, C. R. Webster, M. Cabane, P. Coll, P. G. Conrad, P. D. Archer, S. K. Atreya, A. E. Brunner, et al., Volatile, Isotope, and Organic Analysis of Martian Fines with the Mars Curiosity Rover, Science, 2013, 341(6153), DOI: 10.1126/science.1238937.

66 R. T. Clancy, M. J. Wolff and P. R. Christensen, Mars aerosol studies with the MGS TES emission phase function observations: optical depths, particle sizes, and ice cloud types versus latitude and solar longitude, J. Geophys. Res., 2003, 108(E9), 1-2, DOI: 10.1029/2003JE002058. 
67 J. Audouard, F. Poulet, M. Vincendon, R. E. Milliken, D. Jouglet, J.-P. Bibring, B. Gondet and Y. Langevin, Water in the Martian regolith from OMEGA/Mars Express, J. Geophys. Res.: Planets, 2014, 119(8), 1969-1989, DOI: 10.1002/2014JE004649.

68 R. M. E. Williams, J. P. Grotzinger, W. E. Dietrich, S. Gupta, D. Y. Sumner, R. C. Wiens, N. Mangold, M. C. Malin, K. S. Edgett, S. Maurice, et al., Martian Fluvial Conglomerates at Gale crater, Science, 2013, 340(6136), 1068-1072, DOI: 10.1126/science.1237317.

69 M. C. Palucis, W. E. Dietrich, A. G. Hayes, R. M. E. Williams, S. Gupta, N. Mangold, H. Newsom, C. Hardgrove, F. Calef and D. Y. Sumner, The origin and evolution of the Peace Vallis fan system that drains to the Curiosity landing area, Gale crater, Mars, J. Geophys. Res.: Planets, 2014, 119(4), 705-728, DOI: 10.1002/2013JE004583.

70 N. Mangold, O. Forni, A. Ollila, R. Anderson, G. Berger, J. C. Bridges, S. M. Clegg, A. Cousin, W. E. Dietrich, S. Gupta, E. Lewin, C. Fabre, O. Gasnault, K. Herkenhoff, S. Le Mouélic, S. Maurice, P.-Y. Meslin, V. Sautter, R. C. Wiens, R. Williams and MSL Science Team, Chemcam Analysis of Conglomerates at Bradbury Site, Mars, 44th Lunar and Planetary Science Conference, held March 18-22, 2013 in The Woodlands, Texas, LPI Contribution No. 1719, March 2013, p. 1267.

71 N. Mangold, O. Forni, G. Dromart, K. Stack, R. C. Wiens, O. Gasnault, D. Y. Sumner, M. Nachon, P. Y. Meslin, R. B. Anderson, B. Barraclough, J. F. Bell III, G. Berger, D. L. Blaney, J. C. Bridges, F. Calef, B. Clark, S. M. Clegg, A. Cousin, L. Edgar, K. Edgett, B. Ehlmann, C. Fabre, M. Fisk, J. Grotzinger, S. Gupta, K. E. Herkenhoff, J. Hurowitz, J. R. Johnson, L. C. Kah, N. Lanza, J. Lasue, S. Le Mouélic, R. Léveillé, E. Lewin, M. Malin, S. McLennan, S. Maurice, N. Melikechi, A. Mezzacappa, R. Milliken, H. Newsom, A. Ollila, S. K. Rowland, V. Sautter, M. Schmidt, S. Schröder, C. d'Uston, D. Vaniman and R. Williams, Chemical variations in Yellowknife Bay formation sedimentary rocks analyzed by ChemCam on board the Curiosity rover on Mars, J. Geophys. Res. Planets, 2015, 120, 452-482, DOI: 10.1002/ 2014 JE004681.

72 A. R. Vasavada, J. P. Grotzinger, R. E. Arvidson, F. J. Calef, J. A. Crisp, S. Gupta, J. Hurowitz, N. Mangold, S. Maurice, M. E. Schmidt, R. C. Wiens, R. M. E. Williams and R. A. Yingst, Overview of the Mars Science Laboratory mission: Bradbury Landing to Yellowknife Bay and beyond, J. Geophys. Res.: Planets, 2014, 119(6), 1134-1161, DOI: $10.1002 / 2014$ JE004622.

73 L. Le Deit, N. Mangold, O. Forni, D. Blaney, A. Cousin, G. Dromart, C. Fabre, M. Fisk, O. Gasnault, N. Lanza, J. Lasue, S. Le Mouélic, S. Maurice, M. Nachon, W. Rapin, M. Rice, V. Sautter, S. Schröder, D. Sumner and R. C. Wiens, The Potassic Sedimentary Rocks in Gale crater, Mars as Seen by ChemCam On-board Curiosity, 46th Lunar and Planetary Science Conference, held March 16-20, 2015 in The Woodlands, Texas, LPI Contribution No. 1832, March 2015, p. 1438.
74 M. Nachon, S. M. Clegg, N. Mangold, S. Schröder, L. C. Kah, G. Dromart, A. Ollila, J. R. Johnson, D. Z. Oehler, J. C. Bridges, S. Le Mouélic, O. Forni, R. C. Wiens, R. B. Anderson, D. L. Blaney, J. F. Bell, B. Clark, A. Cousin, M. D. Dyar, B. Ehlmann, C. Fabre, O. Gasnault, J. Grotzinger, J. Lasue, E. Lewin, R. Léveillé, S. McLennan, S. Maurice, P.-Y. Meslin, W. Rapin, M. Rice, S. W. Squyres, K. Stack, D. Y. Sumner, D. Vaniman and D. Wellington, Calcium sulfate veins characterized by ChemCam/Curiosity at Gale crater, Mars, J. Geophys. Res.: Planets, 2014, 119(9), 1991-2016, DOI: 10.1002/ 2013JE004588.

75 S. M. McLennan, R. B. Anderson, J. F. Bell, J. C. Bridges, F. Calef, J. L. Campbell, B. C. Clark, S. Clegg, P. Conrad, A. Cousin, et al., Elemental Geochemistry of Sedimentary Rocks at Yellowknife Bay, Gale crater, Mars, Science, 2014, 343(6169), 1244734, DOI: 10.1126/science.1244734.

76 D. T. Vaniman, D. L. Bish, D. W. Ming, T. F. Bristow, R. V. Morris, D. F. Blake, S. J. Chipera, S. M. Morrison and A. H. Treiman, Rampe, and 435 coauthors, Mineralogy of a Mudstone at Yellowknife Bay, Gale crater, Mars, Science, 2014, 343(6169), 1243480, DOI: 10.1126/ science.1243480.

77 M. S. Rice, E. A. Cloutis, J. F. Bell, D. L. Bish, B. H. Horgan, S. A. Mertzman, M. A. Craig, R. W. Renaut, B. Gautason and B. Mountain, Reflectance spectra diversity of silica-rich materials: sensitivity to environment and implications for detections on Mars, Icarus, 2013, 223(1), 499-533, DOI: 10.1016/j.icarus.2012.09.021.

78 R. E. Kronyak, L. C. Kah, M. Nachon, N. Mangold, R. C. Weins, R. Williams, J. Schieber and J. Grotzinger, Distribution of Mineralized Veins from Yellowknife Bay to Mount Sharp, Gale crater, Mars: Insight from Textural and Compositional Variation, 46th Lunar and Planetary Science Conference, held March 16-20, 2015 in The Woodlands, Texas, LPI Contribution No. 1832, March 2015, p. 1903.

79 R. J. Léveillé, J. Bridges, R. C. Wiens, N. Mangold, A. Cousin, N. Lanza, O. Forni, A. Ollila, J. Grotzinger, S. Clegg, K. Siebach, G. Berger, B. Clark, C. Fabre, R. Anderson, O. Gasnault, D. Blaney, D. Lauren, L. Laurie, M. Sylvestre and N. Horton, Chemistry of fracture-filling raised ridges in Yellowknife Bay, Gale crater: window into past aqueous activity and habitability on Mars, J. Geophys. Res.: Planets, 2014, 119(11), 2398-2415, DOI: 10.1002/2014JE004620.

80 L. C. Kah, R. Kronyak, J. Van Beek, M. Nachon, N. Mangold, L. Thompson, R. Wiens, J. Grotzinger, J. Farmer, M. Minitti, J. Schieber and D. Oehler, Diagenetic Crystal Clusters and Dendrites, Lower Mount Sharp, Gale crater, 46th Lunar and Planetary Science Conference, held March 16-20, 2015 in The Woodlands, Texas, LPI Contribution No. 1832, March 2015, p. 1901.

81 O. Gasnault, R. B. Anderson, O. Forni, S. Maurice, R. C. Wiens and P. Pinet, Classification of ChemCam Targets Along the Traverse of Curiosity at Gale, Eighth International Conference on Mars, held July 14-18, 2014 in 
Pasadena, California, LPI Contribution No. 1791, July 2014, p. 1269.

82 A. A. Freaman, Materials and Surface Processes at Gale crater and the Moons of Mars Derived from High Spatial and Spectral Resolution Orbital Datasets, Ph.D. Thesis, Washington University, St. Louis, 2014, Publication Number: AAT 3619813, ISBN: 9781303893384, Source: Dissertation Abstracts International, Section: B, vol. 7508(E), p. 149.

83 R. Anderson, J. C. Bridges, A. Williams, L. Edgar, A. Ollila, J. Williams, M. Nachon, N. Mangold, M. Fisk, J. Schieber, S. Gupta, G. Dromart, R. Wiens, S. Le Mouélic, O. Forni, N. Lanza, A. Mezzacappa, V. Sautter, D. Blaney, B. Clark, S. Clegg, O. Gasnault, J. Lasue, R. Léveillé, E. Lewin, K. W. Lewis, S. Maurice, H. Newsom, S. P. Schwenzer and D. Vaniman, ChemCam results from the Shaler outcrop in Gale crater, Mars, Icarus, 2015, 249, 2-21, DOI: 10.1016/ j.icarus.2014.07.025.

84 E. Dehouck, A. Gaudin, N. Mangold, L. Lajaunie, A. Dauzères, O. Grauby and E. Le Menn, Weathering of olivine under $\mathrm{CO}_{2}$ atmosphere: a Martian perspective, Geochim. Cosmochim. Acta, 2014, 135, 170-189, DOI: 10.1016/j.gca.2014.03.032.

85 P. Sobron, A. Wang and F. Sobron, Extraction of compositional and hydration information of sulfates from laser-induced plasma spectra recorded under Mars atmospheric conditions-Implications for ChemCam investigations on Curiosity rover, Spectrochim. Acta, Part B, 2012, 68, 1-16, DOI: 10.1016/j.sab.2012.01.002.

86 M. Ossorio, A. E. S. Van Driessche, P. Pérez and J. M. GarcíaRuiz, The gypsum-anhydrite paradox revisited, Chem. Geol., 2014, 386, 16-21, DOI: 10.1016/j.chemgeo.2014.07.026.

87 N. L. Lanza, R. C. Wiens, R. E. Arvidson, B. C. Clark, W. W. Fischer, R. Gellert, J. P. Grotzinger, J. A. Hurowitz, S. M. McLennan, R. V. Morris, M. S. Rice, J. F. Bell, J. A. Berger, D. L. Blaney, J. G. Blank, N. T. Bridges, F. Calef, J. L. Campbell, S. M. Clegg, A. Cousin, K. S. Edgett, C. Fabre, M. R. Fisk, O. Forni, J. Frydenvang, K. R. Hardy, C. Hardgrove, J. R. Johnson, L. C. Kah, J. Lasue, S. Le Mouelic, M. C. Malin, N. Mangold, J. Martin-Torres, S. Maurice, M. J. McBride, D. W. Ming, H. E. Newsom, S. Schroder, L. M. Thompson, A. H. Treiman, S. VanBommel, D. T. Vaniman and M.-P. Zorzano, Oxidation of Manganese at Kimberley, Gale crater: More Free Oxygen in Mars' Past?, 46th Lunar and Planetary Science Conference, held March 16-20, 2015 in The Woodlands, Texas, LPI Contribution No. 1832, March 2015, p. 2893.

88 W. Goetz, P. Bertelsen, C. S. Binau, H. P. Gunnlaugsson, S. F. Hviid, K. M. Kinch, D. E. Madsen, M. B. Madsen, M. Olsen, R. Gellert, G. Klingelhöfer, D. W. Ming, R. V. Morris, R. Rieder, D. S. Rodionov, P. A. de Souza Jr, C. Schröder, S. W. Squyres, T. Wdowiak and A. Yen, Indication of drier periods on Mars from the chemistry and mineralogy of atmospheric dust, Nature, 2005, 436, 62-65.
89 D. W. Ming, R. Gellert, R. V. Morris, R. E. Arvidson, J. Brückner, B. C. Clark, B. A. Cohen, C. d'Uston, T. Economou, I. Fleischer, G. Klingelhöfer, T. J. McCoy, D. W. Mittlefehldt, M. E. Schmidt, C. Schröder, S. W. Squyres, E. Tréguier, A. S. Yen and J. Zipfel, Geochemical properties of rocks and soils in Gusev crater, Mars: Results of the Alpha Particle X-ray Spectrometer from Cumberland Ridge to Home Plate, J. Geophys. Res., 2008, 113, E12S39, DOI: 10.1029/2008JE003195.

90 W. Goetz, P. Bertelsen, C. S. Binau, F. Folkmann, H. P. Gunnlaugsson, J. í Hjøllum, S. F. Hviid, J. Jensen, K. M. Kinch, K. Leer, D. E. Madsen, J. Merrison, M. Olsen, H. M. Arneson, J. F. Bell III, R. Gellert, K. E. Herkenhoff, J. R. Johnson, M. J. Johnson, G. Klingelhöfer, E. McCartney, D. W. Ming, R. V. Morris, J. B. Proton, D. Rodionov, M. Sims, S. W. Squyres, T. Wdowiak and A. S. Yen, Overview of the magnetic properties experiments on the Mars Exploration Rovers, J. Geophys. Res., 2009, 114, E06S90, DOI: 10.1029/2008JE003098.

91 P. R. Christensen, R. V. Morris, M. D. Lane, J. L. Bandfield and M. C. Malin, Global mapping of Martian hematite mineral deposits: remnants of water-driven processes on early Mars, J. Geophys. Res., 2001, 106(E10), 23873-23886, DOI: $10.1029 / 2000 J E 001415$.

92 R. E. Arvidson, P. Bellutta, F. Calef, A. A. Fraeman, J. B. Garvin, O. Gasnault, J. A. Grant, J. P. Grotzinger, V. E. Hamilton, M. Heverly, K. A. Iagnemma, J. R. Johnson, N. Lanza, S. Le Mouélic, N. Mangold, D. W. Ming, M. Mehta, R. V. Morris, H. E. Newsom, N. Rennó, D. Rubin, J. Schieber, R. Sletten, N. T. Stein, F. Thuillier, A. R. Vasavada, J. Vizcaino and R. C. Wiens, Terrain physical properties derived from orbital data and the first 360 Sols of Mars Science Laboratory Curiosity rover observations in Gale crater, J. Geophys. Res.: Planets, 2014, 119(6), 1322-1344, DOI: 10.1002/2013JE004605.

93 S. Gupta, D. M. Rubin, M. S. Rice, K. W. Lewis and K. Stack, et al., Makingsense of Martian sediments at the Kimberley, Gale crater, AGU Fall Meeting Abstracts, vol. 1, 12/2014, p. 02.

94 A. H. Treiman, D. L. Bish, D. T. Vaniman, et al., Mineralogy, Provenance, and Diagenesis of a Potassic Basaltic Sandstone on Mars: CheMin X-ray Diffraction of the Windjana Sample (Kimberley Area, Gale crater), J. Geophys. Res.: Planets, 2015, 121(1), 75-106, DOI: 10.1002/ 2015JE004932.

95 J. A. Berger, M. E. Schmidt, R. Gellert and M. R. Fisk, Zinc Enrichments in the Rocks of Gale crater, Mars Measured by MSL-APXS Reflect Both High Zn in Jake_M Rocks and the Concentration of $\mathrm{Zn}$ in Sedimentary Cements, American Geophysical Union, Fall Meeting, 2014, abstract \#P51E3988.

96 F. Moynier, F. Albarède and G. F. Herzog, Isotopic composition of zinc, copper, and iron in lunar samples, Geochim. Cosmochim. Acta, 2006, 70(24), 6103-6117, DOI: 10.1016/j.gca.2006.02.030.

97 J. P. Grotzinger, D. Y. Sumner, L. C. Kah, K. Stack, S. Gupta, L. Edgar, D. Rubin, K. Lewis, J. Schieber, N. Mangold, et al., 
A Habitable Fluvio-Lacustrine Environment at Yellowknife Bay, Gale crater, Mars, Science, 2014, 343(6169), 1242777, DOI: $10.1126 /$ science.1242777.

98 K. L. Siebach, J. P. Grotzinger, L. C. Kah, K. M. Stack, M. Malin, R. Léveillé and D. Y. Sumner, Subaqueous shrinkage cracks in the Sheepbed mudstone: implications for early fluid diagenesis, Gale crater, Mars, J. Geophys. Res.: Planets, 2014, 119(7), 1597-1613, DOI: 10.1002/ 2014JE004623.

99 J. C. Bridges, S. P. Schwenzer, R. Leveille, F. Westall, R. C. Wiens, N. Mangold, T. Bristow, P. Edwards and G. Berger, Diagenesis and clay mineral formation at Gale crater, Mars, J. Geophys. Res.: Planets, 2015, 120, 1-19, DOI: 10.1002/2014JE004757.

100 S. Giguere, T. Boucher, C. Carey, M. D. Dyar and S. Mahadevan, A framework for fully-customized baseline removal, Sci-X, Providence, RI, 2015, p. 288.

101 M. D. Dyar, T. Boucher, C. Carey, S. Giguere and S. Mahadevan, Choices and improvements in baseline removal in LIBS spectroscopy, Sci-X, Providence, RI, 2015, p. 138.

102 A. Tara, B. J. Bornstein, D. M. Gaines, R. C. Anderson, D. R. Thompson, M. Burl, R. Castaño and M. Judd, AEGIS automated science targeting for the MER Opportunity rover, ACM Transactions on Intelligent Systems and Technology, vol. 3, Issue 3, 05/2012, DOI: 10.1145/ 2168752.2168764.

103 T. Estlin, D. Gaines, B. Bornstein, S. Schaffer, V. Tompkins, D. R. Thompson, A. Altinok, R. C. Anderson, M. Burl, R. Castaño, D. Blaney, L. De Flores, T. Nelson and R. Wiens, Automated targeting for the MSL rover ChemCam spectrometer, in 12th International Symposium on Artificial Intelligence, Robotics, and Automation in Space (i-SAIRAS), June, Montreal, Canada, 2014, pp. 17-19.

104 J. R. Johnson, J. F. Bell, S. Bender, D. Blaney, E. Cloutis, L. DeFlores, B. Ehlmann, O. Gasnault, B. Gondet, K. Kinch, M. Lemmon, S. Le Mouélic, S. Maurice, M. Rice and R. C. Wiens, ChemCam passive reflectance spectroscopy of surface materials at the Curiosity landing site, Icarus, 2015, 249, 74-92, DOI: 10.1016/ j.icarus.2014.02.028.

105 T. H. McConnochie, M. D. Smith, S. Bender, M. J. Wolff, J. R. Johnson, M. T. Lemmon, R. C. Wiens, S. Maurice, O. Gasnault, D. Blaney, L. P. DeFlores, A.-M. Harri, O. Kemppinen, M. Genzer, J. E. Moores, M. H. Wong, M. G. Trainer, F. J. Martin-Torres, M.-P. Zorzano and M. de la Torre Juarez, ChemCam Passive Spectroscopy of Atmospheric $\mathrm{O}_{2}$ and $\mathrm{H}_{2} \mathrm{O}$, Eighth International Conference on Mars, held July 14-18, 2014 in Pasadena, California, LPI Contribution No. 1791, p. 1328, July 2014.

106 S. M. Clegg, R. Wiens, A. K. Misra, S. K. Sharma, J. Lambert, B. Steven, N. Raymond, K. Nowak-Lovato, S. Smrekar, M. Darby Dyar and S. Maurice, Planetary Geochemical Investigations Using Raman and Laser-Induced Breakdown Spectroscopy, Appl. Spectrosc., 2014, 68(9), DOI: 10.1366/13-07386.

107 S. Maurice, R. C. Wiens, R. Anderson, O. Beyssac, L. Bonal, S. Clegg, L. DeFlores, G. Dromart, W. Fischer, O. Forni, O. Gasnault, J. Grotzinger, J. Johnson, J. Martinez-Frias, N. Mangold, S. McLennan, F. Montmessin, F. Rull, S. Sharma, T. Fouchet and F. Poulet, SuperCam Team, Science Objectives of the SuperCam Instrument for the Mars2020 Rover, 46th Lunar and Planetary Science Conference, held March 16-20, 2015 in The Woodlands, Texas, LPI Contribution No. 1832, p. 2818, March 2015. 